Provided for non-commercial research and education use. Not for reproduction, distribution or commercial use.

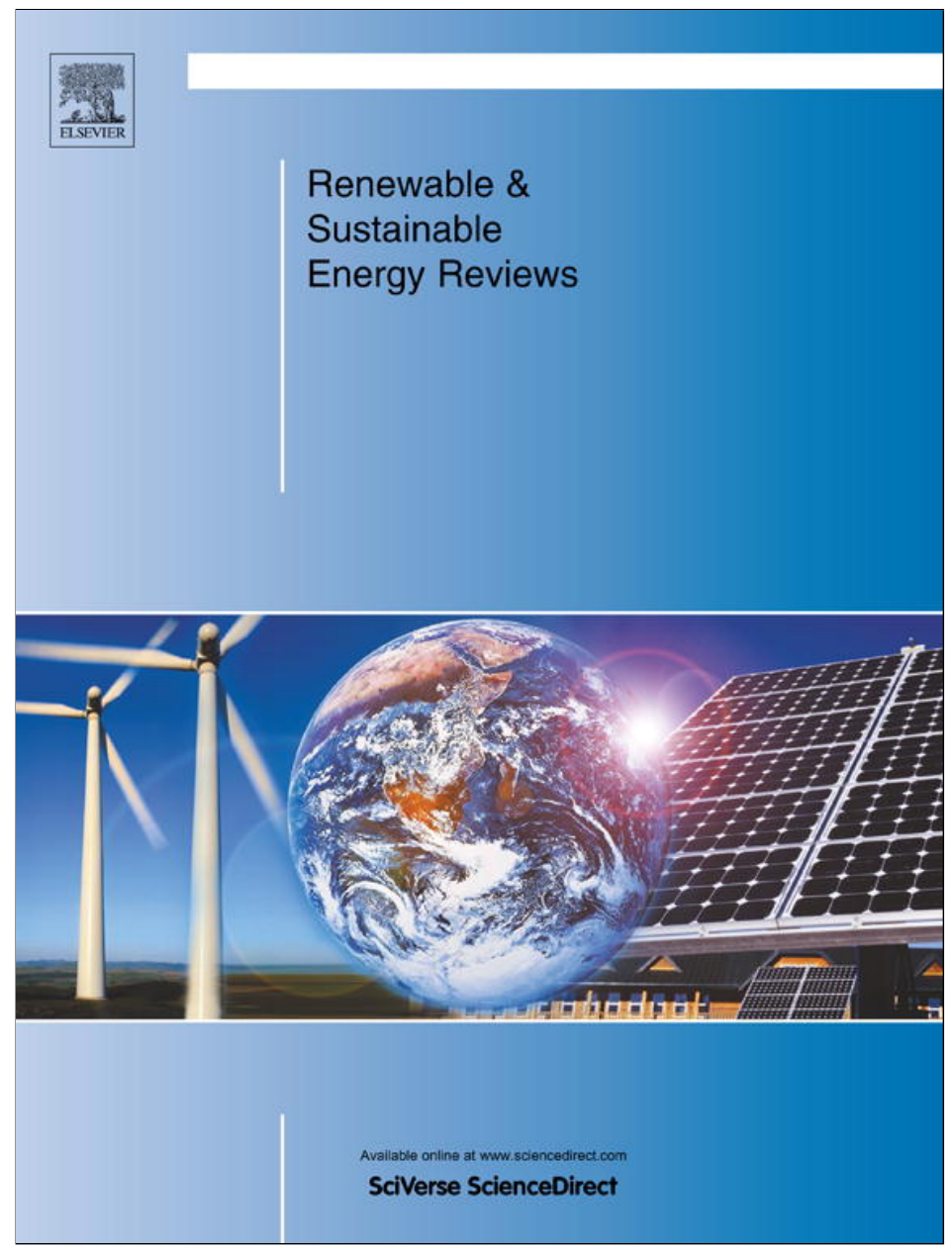

(This is a sample cover image for this issue. The actual cover is not yet available at this time.)

This article appeared in a journal published by Elsevier. The attached copy is furnished to the author for internal non-commercial research and education use, including for instruction at the authors institution and sharing with colleagues.

Other uses, including reproduction and distribution, or selling or licensing copies, or posting to personal, institutional or third party websites are prohibited.

In most cases authors are permitted to post their version of the article (e.g. in Word or Tex form) to their personal website or institutional repository. Authors requiring further information regarding Elsevier's archiving and manuscript policies are encouraged to visit:

http://www.elsevier.com/copyright 


\title{
Load mismatch of grid-connected photovoltaic systems: Review of the effects and analysis in an urban context
}

\author{
Aldo Orioli*, Alessandra Di Gangi \\ D.D.E. Dipartimento dell'Energia, Università degli Studi di Palermo, Viale delle Scienze Edificio 9, Palermo 90128, Italy
}

\section{A R T I C L E I N F O}

\section{Article history:}

Received 12 June 2012

Received in revised form

28 November 2012

Accepted 9 December 2012

\section{Keywords:}

Load mismatch

Mismatch

Grid-connected photovoltaic systems

Photovoltaic

\begin{abstract}
A B S T R A C T
The mismatch between generated and consumed electricity is a relevant topic of the energy and economic assessment of photovoltaic (PV) systems. Due to the load mismatch some amount of PV electricity may be exported to the grid because the electrical demand is temporarily lower than production, whereas a consumption, which is higher than production and/or that does not match the available PV generation, will require to be supplemented by the public grid electricity. The presence of the load mismatch can cause the effect of disadvantageously purchasing electricity from the grid and/or squandering the unexploited PV energy. If only a very small part of the PV generation is used to supply the household appliances, benefits may not compensate disbursements. Moreover, instead of giving a benefit to the community, an amount of surplus electricity generated by a great number of PV systems may represent a significant problem for the grid operators.

In this paper the study of the effect of the load mismatch on the energy and economic analysis of the PV potential of a district of a city of the South Italy is presented. The authors propose an appropriate methodology able to explore the architectural morphology of buildings and evaluate both the solar potential of PV systems installed on roofs and the economic aspects involved. The impact on the grid of the electricity generated by large-scale PV systems, which is a worry to the traditional electricity producers and dispatchers, seems to be much less than expected if the economic viability is considered in the assessment of the real penetration of PV systems. The results, which confirmed the importance of the role played by the load mismatch, suggest that only the generation of the PV electricity that is really consumed by the PV producers should be wisely supported by the economic incentives.
\end{abstract}

(c) 2012 Elsevier Ltd. All rights reserved.

\section{Contents}

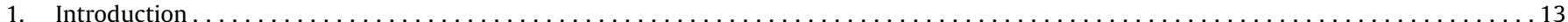

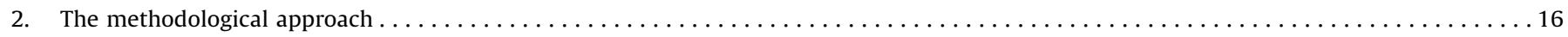

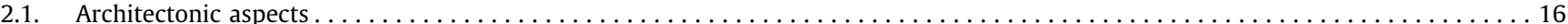

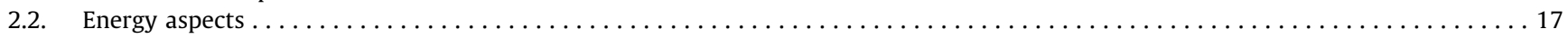

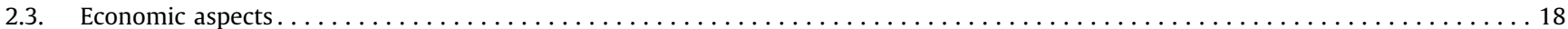

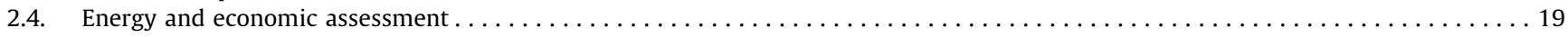

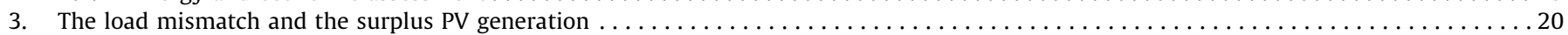

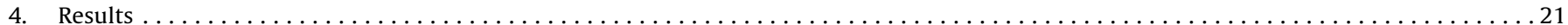

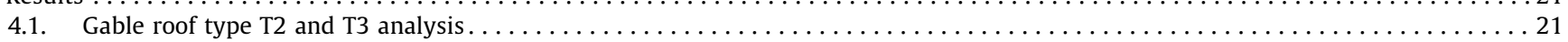

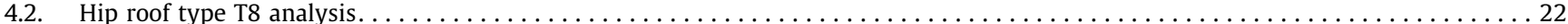

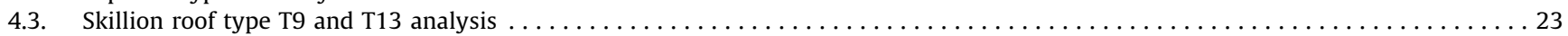

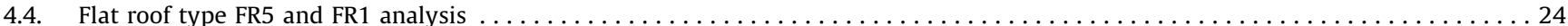

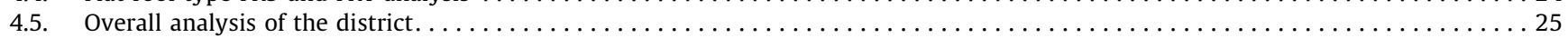

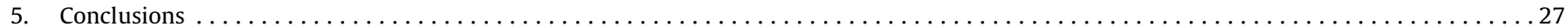

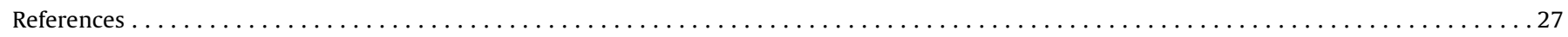

\footnotetext{
*Corresponding author. Tel.: + 39091 23861914x905; fax: + 39091484425.

E-mail address: orioli@dream.unipa.it (A. Orioli).
} 


\author{
Nomenclature \\ $C_{P V} \quad$ Gross energy cover factor of the district [\%] \\ $c_{u} \quad$ Utilization coefficient $c_{u}$ \\ $D_{\text {Day }} \quad$ Electricity demand of the standard flat from dawn to \\ dusk [kWh] \\ $D_{\text {Day }, j} \quad$ Electricity demand of the generic $j$-th PV system from \\ dawn to dusk [kWh] \\ $D_{j}^{*} \quad$ Electricity demand of the generic $j$-th PV \\ system [kWh] \\ $D_{j} \quad$ Electricity demand of the generic $j$-th PV system \\ during the generic $i$-th time interval [kWh] \\ $D_{\text {Match }}$ Matched energy demand of the generic $j$-th PV \\ system [kWh] \\ $D_{\text {Mism,j }} \quad$ Mismatched energy demand of the generic $j$-th PV \\ system [kWh] \\ $D_{\text {Night }} \quad$ Electricity demand of the standard flat from dusk to \\ dawn [kWh] \\ $D_{\text {Night }, j} \quad$ Electricity demand of the generic $j$-th PV system from \\ dusk to dawn [kWh]
}

\begin{tabular}{|c|c|}
\hline$D_{\text {Total }}$ & Yearly electricity demand of the district [kWh] \\
\hline$E_{\text {exp }, j}$ & $\begin{array}{l}\text { Electricity exported by the generic } j \text {-th PV system } \\
\text { during the generic } i \text {-th time interval [kWh] }\end{array}$ \\
\hline$E_{\text {grid } j}$ & $\begin{array}{l}\text { Electricity exchanged with the grid by the generic } j \text {-th } \\
\text { PV system during the generic } i \text {-th time interval [ } \mathrm{kWh}]\end{array}$ \\
\hline$E_{i m p, j}$ & $\begin{array}{l}\text { Electricity imported by the generic } j \text {-th PV system } \\
\text { during the generic } i \text {-th time interval [kWh] }\end{array}$ \\
\hline$E_{P V, j}^{*}$ & $\begin{array}{l}\text { Yearly electricity produced by the generic } j \text {-th PV } \\
\text { system [kWh] }\end{array}$ \\
\hline$E_{P V, j}$ & $\begin{array}{l}\text { Electricity generated by the generic } j \text {-th PV system } \\
\text { during the generic } i \text {-th time interval [kWh] }\end{array}$ \\
\hline$E_{P V l o a d, j}^{*}$ & $\begin{array}{l}\text { Electricity supplied to the load by the generic } j \text {-th PV } \\
\text { system [kWh] }\end{array}$ \\
\hline$E_{\text {PVloac }}$ & $\begin{array}{l}\text { Electricity supplied to the load by the generic } j \text {-th PV } \\
\text { system during the generic } i \text {-th time interval [kWh] }\end{array}$ \\
\hline$E_{P V T}$ & Yearly electricity produced by all PV systems [kWh] \\
\hline & Number of samples in the evaluation period \\
\hline$N_{P V}$ & tems \\
\hline$\gamma_{D}$ & h index of the di \\
\hline D,j & Load match index of the generic $j$-th PV system [\% \\
\hline
\end{tabular}

\section{Introduction}

Since 2005, when Kyoto protocol legislations were implemented in order to enforce the reduction of $\mathrm{CO}_{2}$ emissions resulting from the use of fossil fuel, promoting renewable energy sources (RES) has become a priority and, for encouraging the installation of RES-based generation systems, many countries have wisely adopted different support policies. The European Union (EU) has set binding targets for the dissemination of the renewable energy sources (RES) until 2020, known as the "20-20-20" targets. In particular, with the Directive 2009/28/EC, Italy is obliged to ensure that $17 \%$ of the final energy consumption in 2020 comes from RES.

Buildings are responsible for a considerable share of energy consumption, and will play a growing role in the energy demands of emerging economies in the next decades. Cities are the places where great amounts of electricity are consumed, but power stations cannot be installed amid blocks of flats. Using electricity in the same place where it is produced it is very gainful for both the self-producing consumer, whose energy bills will lower, and the electrical manufacturers and grid operators that will reduce costs for transmission and distribution. Cities are often composed of multi-storey buildings containing many flats that are covered by the same roof, which is a common property of all homeowners. Because each homeowner can use only a part of the common roof to install a PV system, the number of floors affects to the possibility of freely harvesting the solar energy collected by the building roof. As a consequence, it may be difficult to adequately cover the electricity demand of the households dwelling in multistorey buildings and even the economic investments may result unprofitable.

For this reason, it is important to accurately analyze the energy and economic performance of the system to correctly estimate the profit of the investment. The assessment of the economic feasibility of PV systems requires an accurate analysis based on the evaluation of all costs and benefits. The crucial factors involved in the assessment are the value of the discount rate, PV devices costs, selling and purchasing power prices and feed-in tariffs (FIT). These variables have to be carefully considered because they can rapidly change due the financial situation, the government energy policies and the trend in the market of PV devices and fossil fuels. Other costs, which are often overlooked, regard the indemnity insurance and the equipment maintenance, servicing and replacement of the PV system.

Even the mismatch between generated and consumed electricity may produce relevant effects in the viability of PV systems. Because the instantaneous perfect correspondence between demand and generation is quite improbable, a part of the demanded electricity may be not covered by the PV generation or the energy generated by the PV systems may be greater than the electricity demand. The PV energy surplus may represent an important issue:

1) for the electricity transmission grid operators: the unpredictable presence in the grid of PV generated energy can increase the difficulties in dealing with short-term transients, electricity load, non-dispatchable power and intermittency;

2) for the PV system owners: the investment may result not economically convenient because the selling price of electricity is generally less than the purchase price;

3 ) for the country: an energy policy that economically supports the PV electricity generated, even it is not really consumed, may be responsible of high levels of greenhouse gas emission and fossil fuel importation.

The problem of the load mismatch was studied by many authors. Paatero et al. [1] analyzed for Lisbon and Helsinki climates the effects of a high level of photovoltaics connected in the middle voltage distribution network. They found that the mismatch between PV production and domestic electricity consumption, which in their cases appeared in the early evening hours, could not be fully compensated through orientation of the PV panels. PV integration up to $50 \%$ of annual domestic load would positively influence both the voltage and network losses without increasing the voltage of the grid. Denholm et al. [2] considered the constraint of traditional electricity generation plants to reduce output and accept PV generated energy. Basing on the power system flexibility concept, they deduced that there was a somewhat absolute limit to the economic integration of PV sources in Texas, USA. Even with a completely flexible power system, which can reduce to zero the electricity produced, providing $50 \%$ of the systems energy from PV appears to be close to the technical limit. Denholm et al. [3] also tried to increase the usefulness of PV generation dealing with different 
possibilities: load shifting, energy storage, ramping capability and flexibility of conventional generators. Even after increasing system flexibility, some additional accommodation would be made for the excess of PV energy generated in non-summer seasons. They found that a storage system capable of storing the average daily demand would provide about $50 \%$ of the system's energy. Load shifting would require the development of real-time price signals and smart control systems of appliances and devices. To reach such a purpose, a radical transformation of the electricity systems, from centrally controlled to highly distributed and interactive systems, would be required.

Stodola et al. [4] faced the problem of evaluating the maximum deployment that would permit $95 \%$ of the annual output from PV to be utilized without reducing the output of the baseload plants located in 32 regions of USA. Without considering the problems related to the grid flexibility, they compared the energy produced by dual tracking, azimuth-tracking and fixed tilted panels, and calculated that $7.8 \%$ of the total annual electricity demand could be met by installing $59 \mathrm{GW}$ of PV panels. They also compared the PV energy prices to the cost of baseload power and the costs of the dispatchable power stations that PV systems would replace. Passey et al. [5] analyzed the potential impact of integrating photovoltaics in the Western Australian electricity networks. Using the marginal cost administrative prices to assess the economic convenience, they explored the possibility of offsetting baseload and/or peaking generation, deferring network augmentation and reducing line losses. The present values earned by PV offsetting conventional baseload and peaking generation resulted significant compared to its installed cost. In contrast, the present values earned by PV in deferring network augmentation and reducing line losses on the main grid were very low, compared to its installed, and very site specific.

Solomon et al. [6] studied the penetration of PV generation in Israel achieved with no-dump (ND) systems, which were defined as the largest PV systems that could deliver all their annual production to the grid without any need for spillage. They stated that a grid flexibility of $65 \%$ represents the limit above which no intake of energy from ND-sized systems is allowed without dumping. With a grid flexibility of $65 \%$ a no-dump PV system could have contributed a maximum of $2.7 \%$ to annual fuel saving of the grid; the contribution could have been increased to $10.4 \%$ by enlarging the PV system size and allowing $5 \%$ of its annual output to be dumped. Solomon et al. [7] extended their study including the use of 1 - and 2-axis sun tracking, and 2-axis concentrator PV technologies. Moreover they analyzed the effect of very large-scale PV power plants, even considering their influence on grid ramping requirements. They found that for grid flexibilities above $70 \%$ the tested PV technologies of ND-sized systems begin to produce significantly larger grid penetration than the static fixed-panel situation. In a further paper Solomon et al. [8] investigated the appropriate storage size and the available technologies in order to achieve high grid penetration for various grid flexibilities.

The above researchers addressed the PV penetration mainly considering the energy aspects of the problem. Myers et al. [9] provided an assessment of the large-scale implementation of distributed photovoltaics in Wisconsin, USA, considering both the energy and economic aspects of the problem. They evaluated a state wide aggregate annual capacity factor of $13.3 \%$ and found that with a flexibility factor of $60 \%$, which is representative of the analyzed electricity infrastructure, the corresponding contribution level of PV approached a limit of $20 \%$ of annual energy. The results of the energy assessment confirmed the data issued by Denholm et al. in their study of Texas: with a $60 \%$ flexibility factor the percentage of system energy from PV approached a limit of $20 \%$, with $80 \%$ flexibility a limit of $35 \%$ and with $100 \%$ flexibility a limit of $50 \%$. The economics of residential or light-commercial scale PV systems, with no incentives, were analyzed based on the levelized cost of the PV generated electricity, the net present value of the investment and the benefit-to-cost ratio. The assessment, which was calculated over a period of 25 years on the basis of a normalized cost per watt, considered realistic values of the inverters lifetime, PV panels time degradation, growth rate of electricity cost and inflation rate. On an economic basis, the investment in distributed solar photovoltaics in Wisconsin was considered not profitable at that time.

Widén et al. [10] presented a methodology for evaluation of options for improved load matching. The method was applied to assess the impact of PV array orientation, demand side management and storage on the matching of PV to demand profiles for detached houses and apartments in Sweden. Storage was found to be the most effective option at high penetration levels, while demand side management was effective or even slightly better at low overproduction levels. Zerhouni et al. [11] presented a method to reach the optimum load matching by the PV array reconfiguration.

To assess the impact of the load mismatch on the PV system owners it is necessary to perform accurate economic analyses in order to reach the most realistic conclusions about the viability of the investment. Actually, the problem of the penetration of the PV generation on the grid becomes an important issue for the PV system owner only when he gets the feeling that the load mismatch may cause him an economic damage because the surplus electricity is sold off whereas the price of the purchased energy remains high. The awareness of the situation can induce each household to try to implement some personal strategies to better exploit the PV generated electricity. The impact of these strategies, whose global result may be very effective, can only be assessed with an accurate energy and economic overview of the problem that includes also the economic point of view of the PV system owners. Actually, before to be concerned about the maximum amount of PV energy that a grid can accept, one should also explore how many PV systems are likely to be installed considering the penalizing effect of the load mismatch on their economic assessment.

In order to study the above issue dealing with photovoltaic systems operating in dense city contexts, a case study already presented by the authors [12] is exhaustively analyzed in this paper. The study case refers to a district of Palermo (Sicily), which is a densely built town in the south of Italy. The district is interesting because adequately represents the mixed combination of ancient and new buildings, which is often present in many European cities. The study has showed the importance of not oversizing the PV systems and the impact of the load mismatch on the profitability of the economic investment. Even the achievement of the "20-20-20" energy targets of the European Union, which is supposed to be reasonable for a sunny southern city whose buildings mostly have a relatively small number of flats, may be seriously questioned due to the economic effect of the load mismatch.

A wise energy policy should consider that only the generation of the PV electricity that is really consumed should be economically supported. Actually, instead of giving a benefit to the community, an amount of surplus electricity generated by a great number of PV systems, which is suddenly and unpredictably transferred to the grid due to the momentary favourable weather conditions or the improper habits in using the electrical appliances, may represent a significant problem in the management of the public grid transmission lines. The study has shown that the impact on the grid of the PV electricity that mismatches the demand should be significantly less than expected if only the PV systems whose economic viability was assessed are installed. 


\section{The methodological approach}

The methodology and the case study are the same that were fully described by Cellura et al. [12] who assessed the photovoltaic potential of a selected urban area of the city of Palermo (Sicily, Italy) using Google Earth ${ }^{\mathrm{TM}}$ to classify buildings, according to their number of floors, the shape, orientation and pitch of roofs. The coverage of the electricity demand was investigated on the basis of the consumption of electricity of the households and the results of the energy assessment were screened considering the economic feasibility of grid-connected photovoltaic systems. The study also considered the main factors influencing the computation, such as the mismatch between generated and consumed electricity and the shading effects due to the surrounding obstacles.

Some parameters were changed in order to update the results and highlight the effect of the load mismatch. The methodology and the results of the case study are briefly summarized in this paragraph. The following points were considered:

\section{- Architectonic aspects:}

- identification of the roof surfaces of buildings;

- estimate of the number of floors of buildings;

- shape classification of roofs.

- Energy aspects:

- estimate of the electricity produced by the PV systems installed on the roofs;

- estimate of the electricity consumed by the households;

- estimate of the coverage of the electricity demand.

- Economic aspects:

- evaluation of costs and benefits of the PV systems;

- identification of the installed PV systems that are economically effective.

- Energy and economic assessment:

- estimate of the coverage of the electricity demand related to the results of the economic analysis;

- sensitivity analysis for the most significant physical and economic parameters.

\subsection{Architectonic aspects}

The analyzed district measures $268.88 \mathrm{~m}^{2}$ and, as it is shown in Fig. 1, is characterized by a regular square layout of streets, well ordered orientation of buildings $\left(117^{\circ}\right.$ East of South and 153

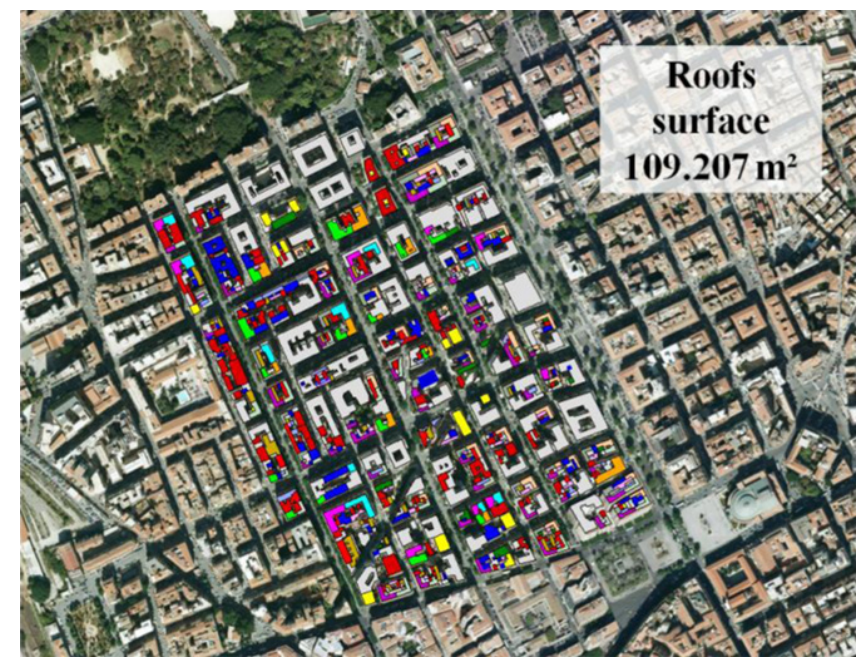

Fig. 1. The analyzed district of Palermo (Sicily).
Roofing distribution

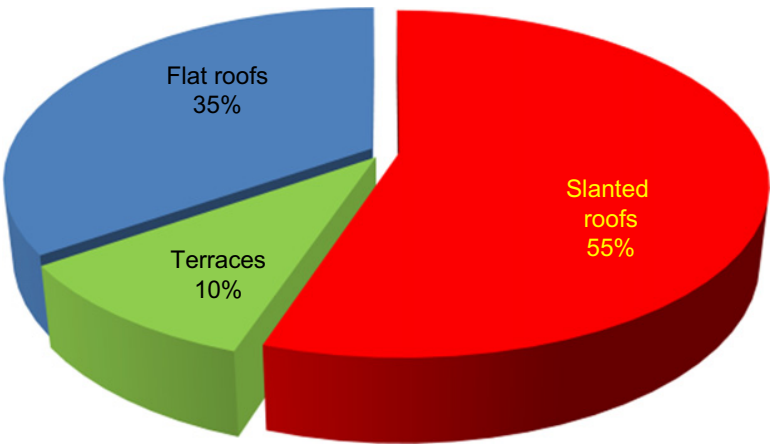

Fig. 2. Percentage distribution of the district roofing.

Percentage distribution of roof areas vs number of floors

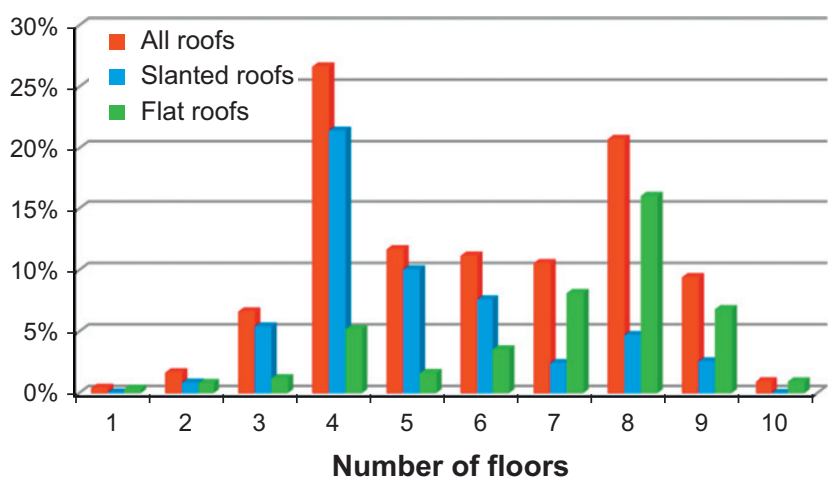

Fig. 3. Distribution of roof areas versus number of floors.

West of South), and almost constant pitch of slanted roofs (about $25^{\circ}$ above the horizontal).

The district area occupied by buildings measures $109,207 \mathrm{~m}^{2}$, which is $40 \%$ of the whole district's surface, and it is subdivided as shown in Fig. 2.

The slanted roofs, which have different shapes (gable, hip and skillion), typically cover old stone buildings characterized by a small number of floors and made with masonry walls distant each other about 4-5 m; the buildings have a standard depth of about $9 \mathrm{~m}$. The buildings contain residential apartments whose gross surface is about $150-170 \mathrm{~m}^{2}$. This building typology is supposed to be very suitable for PV systems because the ratio of roof surface to the number of inhabitants is quite advantageous.

The shape and size of the flat roofs of multi-storey buildings are quite irregular. Despite the large flat roofs, which are supposed to provide a high annual PV electricity production potential, these buildings have several shortcomings mostly related to the shading effects due to balustrades, elevator housings, HVAC equipment, water tanks etc. Moreover, even if this study considered that all flat roofs were exploited by all the building landlords, flat roofing may also be the private terrace of a penthouse flat.

The number of floors of the building, on which depends the amount of roof surface that each co-owner of the building can use to install a PV system, was determined using the Street View function of Google Earth ${ }^{\mathrm{TM}}$. The results of matching the roof areas with the number of floors of the buildings are shown in Fig. 3 .

Most of roofs areas of the analyzed district cover buildings of four floors. Moreover most of the slanted roofs belong to buildings 
Table 1

Classification of roof shapes.

(12)

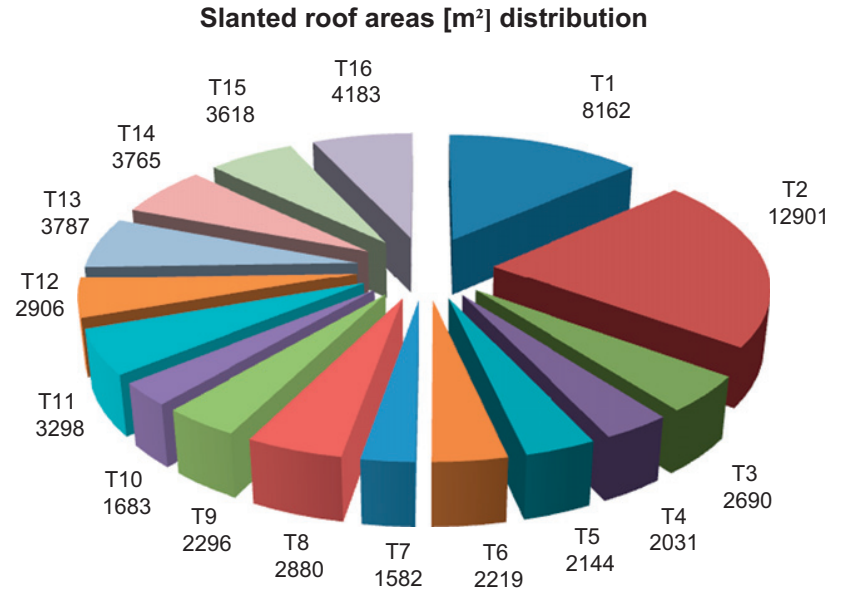

Fig. 4. Surface areas of slanted roofs.

Flat roof areas $\left[\mathrm{m}^{2}\right]$ distribution

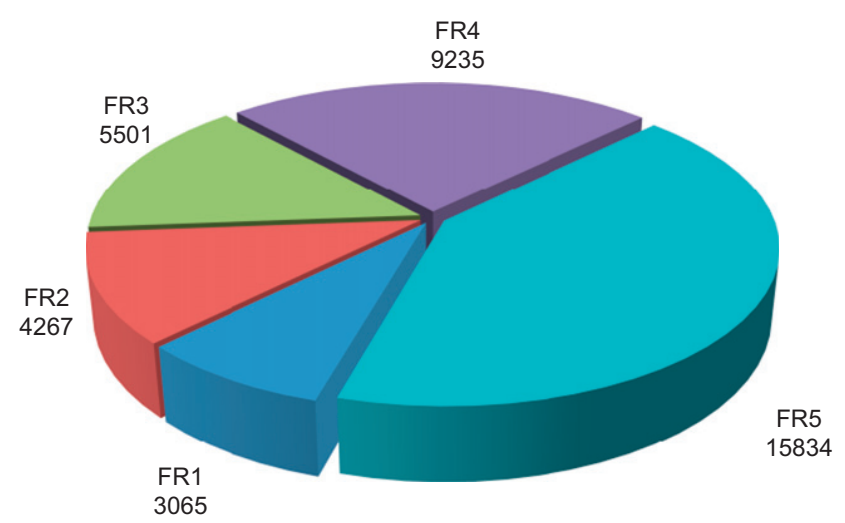

Fig. 5. Surface areas of flat roofs.

of four floors whereas most of the flat roofs cover buildings with eight floors.

The slanted roofs were classified using the 16 types of shapes depicted in Table 1 where the arrows in the pictures indicate the direction where the roof is sloping.

The roof of each building was subdivided in parts similar to the roof types of Table 1; all parts were catalogued by assigning the corresponding roof type, the surface area and the identification code of the building. The obtained results are shown in Fig. 4.
To classify flat roofs, five classes - from FR1 to FR5- containing almost the same number of buildings were identified. Once evaluated the area mean value for each class, five buildings, with a roof area near to the class mean values, were selected to represent the five groups of buildings. The results are depicted in Fig. 5.

\subsection{Energy aspects}

The size of a PV field is related to the available roof surface. For a multi-storey building the portion of the shared roof available for each co-owner depends on the ratio of the area of each flat to the total area of the flats located in the building. The PV fields installed on the flat roofs were sized assuming that

- each flat had a standard surface of $162 \mathrm{~m}^{2}$ and a fixed dimension (width or length) of $9 \mathrm{~m}$;

- the employed PV panel (Kyocera KD210GH-2PU) had the dimensions of $1.50 \times 0.99 \mathrm{~m}$;

- the PV panels were collocated with the same orientation and pitch $\left(25^{\circ}\right.$ above the horizontal) of the slanted roof surface;

- the PV panels installed on flat roofs were oriented to the South with a pitch of $30^{\circ}$, which is the yearly most efficient for the city of Palermo, and placed considering the shadowing caused by the present balustrades, elevator housings and other obstructions.

Contrary to the case study presented by Cellura et al., the PV fields on the slanted roofs were arranged in order to locate on the roofs the maximum number of panels. Modules were flanked without leaving room between them; for routine maintenance only a $0.60 \mathrm{~m}$ wide strip of roof around the PV field was reserved. The decision of maximizing the size of PV fields was made in order to explore what is the effect of oversized PV systems that generate an amount of electricity much greater than the energy demand of the householders. The results of the PV fields sizing are shown in Table 2.

The selected technology was a grid-connected PV system with inverters equipped with maximum power point trackers; batteries to store energy were not used. The inverters were selected matching their nominal power with the size of each PV field. The hourly electricity produced by the PV systems was calculated for 194 combinations of roof type and number of floor using the software PVsyst 5.06 [13]. The values of the hourly electricity generation of each PV system, calculated for a whole year, were summed; the results were divided by the roof area available for each flat and then multiplied by the total surface of each type of slanted or flat roof in order to calculate the PV generation of all slanted roofs of the district. The obtained results are depicted in Figs. 6-8. 
Table 2

Number of PV panels installed on the roofs.

\begin{tabular}{|c|c|c|c|c|c|c|c|c|c|c|}
\hline \multirow[t]{2}{*}{ Roof Type } & \multicolumn{10}{|c|}{ Number of floors } \\
\hline & 1 & 2 & 3 & 4 & 5 & 6 & 7 & 8 & 9 & 10 \\
\hline \multicolumn{11}{|l|}{ Slanted roofs } \\
\hline $\mathrm{T} 1$ & 68 & 32 & 20 & 16 & 12 & 8 & 8 & 8 & 4 & - \\
\hline $\mathrm{T} 2$ & 68 & 32 & 20 & 16 & 12 & 8 & 8 & 8 & 4 & - \\
\hline T3 & 60 & 29 & 18 & 13 & 11 & 8 & 6 & 6 & 6 & - \\
\hline $\mathrm{T} 4$ & 60 & 29 & 18 & 13 & 11 & 8 & 6 & 6 & 6 & - \\
\hline T5 & 60 & 29 & 18 & 13 & 11 & 8 & 6 & 6 & 6 & - \\
\hline T6 & 60 & 29 & 18 & 13 & 11 & 8 & 6 & 6 & 6 & - \\
\hline $\mathrm{T} 7$ & 54 & 26 & 16 & 12 & 10 & 6 & 6 & 4 & 4 & - \\
\hline T8 & 54 & 26 & 16 & 12 & 10 & 6 & 6 & 4 & 4 & - \\
\hline T9 & 85 & 42 & 28 & 21 & 17 & 14 & 12 & 10 & 9 & - \\
\hline T10 & 85 & 42 & 28 & 20 & 16 & 14 & 12 & 10 & 8 & - \\
\hline $\mathrm{T} 11$ & 85 & 42 & 28 & 21 & 17 & 14 & 12 & 10 & 9 & - \\
\hline T12 & 85 & 42 & 28 & 21 & 17 & 14 & 12 & 10 & 9 & - \\
\hline T13 & 75 & 37 & 25 & 18 & 14 & 12 & 10 & 8 & 8 & - \\
\hline T14 & 75 & 37 & 25 & 18 & 14 & 12 & 10 & 8 & 8 & - \\
\hline T15 & 75 & 37 & 25 & 18 & 14 & 12 & 10 & 8 & 8 & - \\
\hline T16 & 75 & 37 & 25 & 18 & 14 & 12 & 10 & 8 & 8 & - \\
\hline \multicolumn{11}{|l|}{ Flat roofs } \\
\hline FR1 & 24 & 12 & 7 & 6 & 4 & 3 & 3 & 3 & 2 & 2 \\
\hline FR2 & 34 & 17 & 11 & 8 & 6 & 5 & 4 & 4 & 3 & 3 \\
\hline FR3 & 39 & 19 & 13 & 9 & 7 & 6 & 5 & 4 & 4 & 3 \\
\hline FR4 & 42 & 21 & 14 & 10 & 8 & 7 & 6 & 5 & 4 & 4 \\
\hline FR5 & 46 & 23 & 15 & 11 & 9 & 7 & 6 & 5 & 5 & 4 \\
\hline
\end{tabular}

\section{Electricity produced by all slanted roofs} [kWh/year]

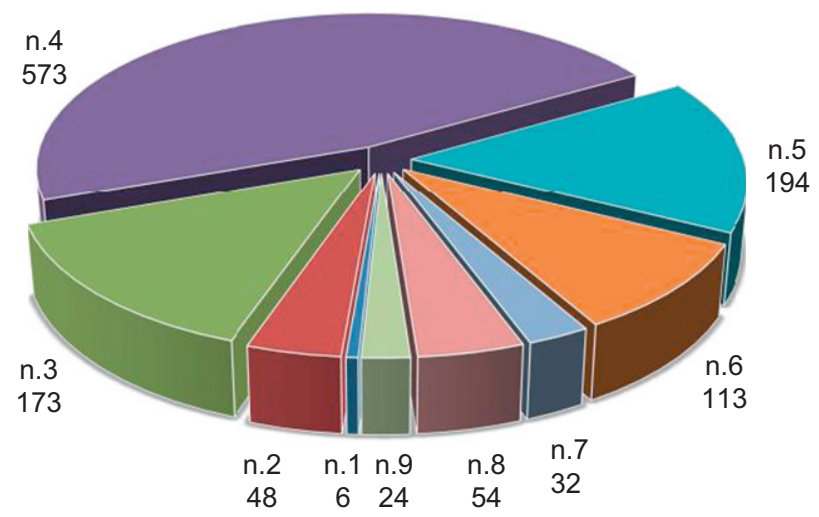

Fig. 6. Electricity produced by all slanted roofs of the district.

\section{Electricity produced by all flat roofs [kWh/year]}

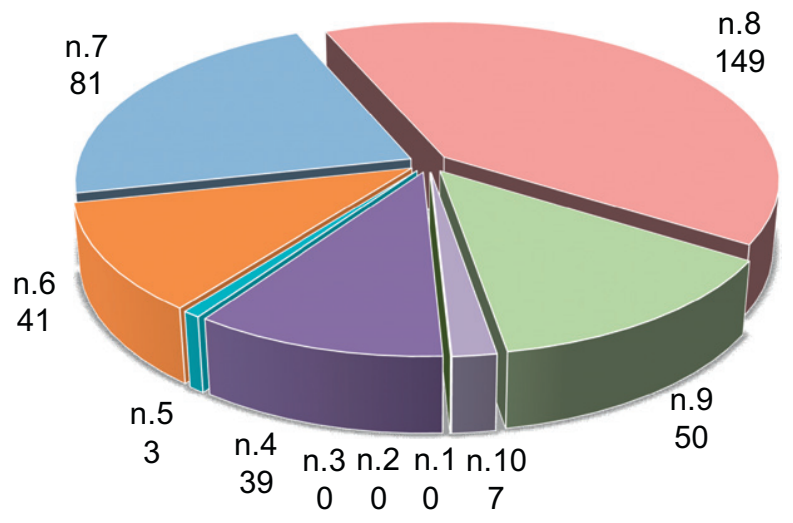

Fig. 7. Electricity produced by all flat roofs of the district.
Electricity produced by all slanted + flat roofs [kWh/year]

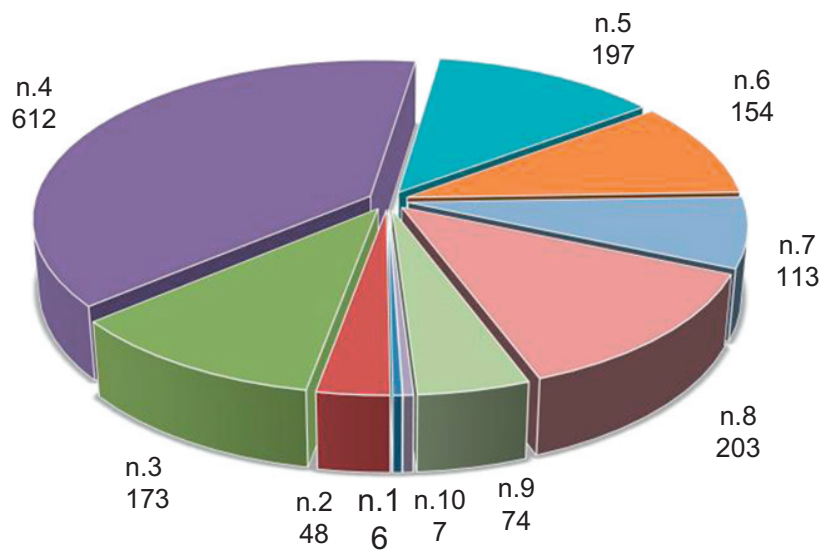

Fig. 8. Electricity produced by all slanted + flat roofs of the district.

In order to assess the average electricity consumption the data officially issued by TERNA [14], which is the main Italian electricity transmission grid operator, and ISTAT, Italian National Institute of Statistics [15], were used; it was calculated that 5.02 people live in the standard flat of $162 \mathrm{~m}^{2}$ and averagely consume $5957.3 \mathrm{kWh}$ of electricity every year.

\subsection{Economic aspects}

To make a judgment about the viability of installing PV systems it is necessary to select the economic evaluation measures that better serve the purpose. The net present value (NPV) and the benefit-to-cost ratio $(\mathrm{B} / \mathrm{C})$ are recommended when the full cost of an alternative has to be considered [16]. The NPV is defined as the sum of the cash flows obtained by algebraically adding the present value of all costs and profits related to the generic year the investment lifetime. NPV, which is used in capital budgeting to analyze the profitability of an investment or project, is sensitive to the reliability of future cash inflows that an investment or project will yield. For accept/reject investment decisions the internal rate of return (IRR) is commonly used. IRR is the discount rate that makes the net present value of all cash flows from a particular project equal to zero. Generally speaking, the higher a project's NPV or IRR, the more desirable it is to undertake the project.

To perform the complete economic analysis all costs and benefits have to be considered for each year of the investment. The disbursements are due to the costs for investment, system devices replacement, maintenance and management, and insurance; the benefits are related to the gain for the avoided electricity bill cost, for incentives and for selling electricity. The costs of the investment were obtained from the market prices of components, considering the cost for labour, fitter's gain and the value added tax (VAT).

In order to avoid that the temporary financial instability observed in Italy in the last months of 2011 improperly influenced the results of the economic analysis, the values of the economic parameters were referred to August 2011, when the effects of the oscillations of the European economic system were still moderate.

The electricity bills were calculated considering the difference between the bills corresponding to the electricity demand and those referred to the difference between the electricity demand and the energy consumed while the PV systems are producing electricity. The electricity tariffs issued by the AEEG-Italian Authority for electricity and gas for domestic consumers with 
an electricity capacity of $3 \mathrm{~kW}$ were used. Table 3 lists the data issued for the third trimester of 2011.

For the incentives, the values of FIT given by the decree issued in 2011 by the Ministry for the Economic Development were assumed. Table 4 list the incentives paid depending on the rated power of the PV system.

For the gain in selling PV electricity, which was calculated on the basis of the exported PV energy, a selling price of $0.103 € / \mathrm{kWh}$ was used. The net gain in selling the exported PV electricity was evaluated charging an income tax of $30.22 \%$, which was estimated on the basis of the average income of the inhabitants of Palermo. The economic analysis was performed also considering:

- a yearly degradation rate in the efficiency of the PV panels equal to $1 \%$ of the nominal initial value:

- yearly maintenance and management costs estimated to be $1 \%$ of the investment cost, for flat roofs, and $2.5 \%$ for slanted roofs;

- a replacement of $1 \%$ of the PV panels every year and of all inverters every five years;

- insurance costs, varying from 184.00 to $307.00 €$ for PV systems with peak power of 3 and $15 \mathrm{kWp}$, respectively;

- a yearly increasing of $5.17 \%$ in the price of electricity;

- a mean selling price of $0.103 € / \mathrm{kWh}$ for the exported PV electricity;

- an inflation rate of $2.05 \%$;

- a current value of $5.20 \%$ of the discount rate;

- a VAT rate of $10 \%$ for all system devices.

All above economic factors were connected to the cash flows obtained by adding algebraically all the costs and all the profits related to the generic year in order to calculate the values of NPV and IRR for a lifetime of the investment of 20 years, which is the period of time when incentives are provided in Italy.

\subsection{Energy and economic assessment}

In order to evaluate the effective coverage of the electricity demand of the district, the results obtained from the energy assessment were coupled with the results of the economic analysis. It was assumed that only the electricity generated by

Table 3

Electricity tariff in Italy.

\begin{tabular}{llll}
\hline Energy $(€ / \mathrm{kWh})$ & & Power $(€ / \mathrm{kW} /$ year $)$ & Fixed cost $(€ /$ year $)$ \\
\hline$<1800 \mathrm{kWh}$ & 0.113146 & 14.53760 & 5.13400 \\
$1800-2640 \mathrm{kWh}$ & 0.161676 & & \\
$2640-4440 \mathrm{kWh}$ & 0.216276 & & \\
$>4440 \mathrm{kWh}$ & 0.261996 & & \\
\hline
\end{tabular}

Table 4

Feed-in tariff for electricity generated by PV systems in Italy.

\begin{tabular}{|c|c|c|}
\hline \multirow{2}{*}{$\begin{array}{l}\text { Rated power } \\
{[\mathrm{kWp}]}\end{array}$} & \multicolumn{2}{|l|}{ August 2011} \\
\hline & $\begin{array}{l}P V \text { systems installed } \\
\text { on buildings } \\
{[€ / \mathrm{kWh}]}\end{array}$ & $\begin{array}{l}P V \text { systems not installed } \\
\text { on buildings } \\
{[€ / \mathrm{kWh}]}\end{array}$ \\
\hline $1-3$ & 0.368 & 0.327 \\
\hline $3-20$ & 0.339 & 0.303 \\
\hline $20-200$ & 0.321 & 0.291 \\
\hline $200-1000$ & 0.303 & 0.263 \\
\hline $1000-5000$ & 0.280 & 0.250 \\
\hline$>5000$ & 0.269 & 0.238 \\
\hline
\end{tabular}

the PV systems, which resulted economically convenient (i.e. characterized by advantageous values of NPV or IRR), was useful to supply the demand of the district. Actually, it is realistic to guess that a PV system is installed on the roof of a house because the homeowner thinks that it is worth to spend the money for that purpose. As a consequence it is very likely that only the PV systems, which were considered economically convenient by homeowners, will be really installed.

For this reason, in assessing the coverage of the electricity demand of the district, the PV systems, whose economic analysis showed disadvantageous values of NPV or IRR, were filtered out and energy produced by them was not included in the calculation.

To assess the level of integration of all $N_{P V}$ PV systems of the district, the produced electricity was compared with the energy demands by means of the gross energy cover factor $C_{P V}$ :

$C_{P V}=\frac{\sum_{j=1}^{N_{P V}} E_{P V, j}^{*}}{\sum_{j=1}^{N_{P V}} D_{j}^{*}} \cdot 100=\frac{E_{P V T o t a l}}{D_{\text {Total }}} \cdot 100$

where $E_{P V, j}^{*}$ and $D_{j}^{*}$ are the yearly PV generation and demand of the $j$-th PV system of the district, respectively; $E_{P V T o t a l}$ and $D_{\text {Total }}$ are the yearly PV generation and demand of the district, respectively. Fig. 9 shows the results of the calculations performed taking account of the available roof areas and the number of floors of all building of the district.

It can be seen that, due to the maximization of the PV fields, the gross energy cover factor surpass the values presented by Cellura et al. who found that PV systems supplied the $35.8 \%$ of the electrical energy required for the district. In particular, slanted roof covered $25.6 \%$ while flat roofs kept a cover factor of $10.2 \%$. A similar distribution of the energy cover factor with the number of floors was found by Cellura et al. Like for the actual case, the energy production was mainly due to the sloped roofs covering buildings of four floors, while the slanted roofs always appeared the most efficient.

Anyway the results shown in Fig. 9 are definitely too optimistic because the energy was calculated without taking account of the lack of solar irradiance due to the shadowing of obstructions, which may be quite likely in a urban context, and possible technical malfunctioning of the PV systems. Fig. 10 shows the yearly gross energy cover factors filtered with the economic criterion.

The comparison with Fig. 9 shows the significant reduction of the gross energy cover factors related to the economic convenience of the PV installations; the gross energy cover factor of the district lowers from $43.9 \%$ to $31.4 \%$, with a percentage decrement of $28 \%$.

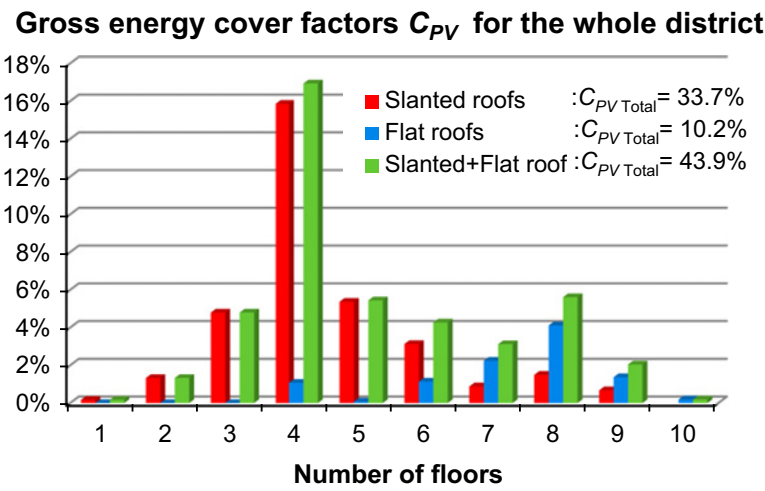

Fig. 9. Yearly gross energy cover factors for the whole district, versus the number of floors. 
Filtered gross energy cover factors $C_{P V}$ for the whole district

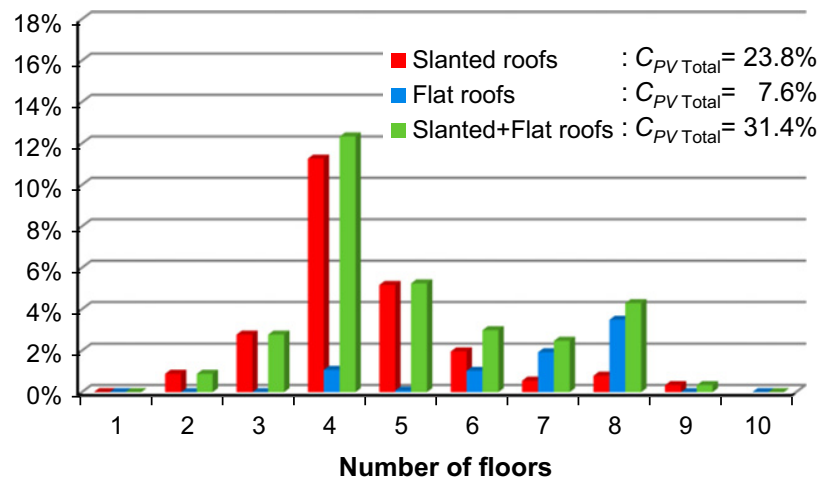

Fig. 10. Yearly gross energy cover factors for the whole district, filtered by the economic assessment, versus the number of floors.

\section{The load mismatch and the surplus PV generation}

The load mismatch is a relevant topic of the assessment of PV systems that has been studied also considering the effects of the use of time-of-using and real-time electricity pricing [17,18]. Due to the load mismatch some amount of PV electricity may be exported to the grid because the PV field is oversized or the electrical demand is temporarily small; the surplus would be sold off because the selling price of electricity is generally less than purchase price. Adversely, a great consumption, which does not match the available PV generation, will require to be supplemented by the grid electricity. The presence of the load mismatch due to the improper habits in using the electrical appliances can cause the occurrence of disadvantageously purchasing electricity from the grid and/or squandering the unexploited PV energy. If only a very small part of the PV generation is used to supply the household appliances, benefits will not compensate disbursements. When almost all PV electricity is used by the household, the economic investment can be very convenient.

The randomness, which characterizes the energy exchange between the grid and the electricity users provided with PV systems, may require a greater degree of grid flexibility and smart energy management strategies. Because the effort required for reaching such objectives may contrast with the economic interests of the traditional electricity producers and dispatchers, the penetration of the PV electricity may meet resistances that are greater than the difficulties related to solving the involved technological problems.

To better analyze the problem, in Fig. 11 the $j$-th PV system of the district is sketched; batteries are not considered.

$E_{P V, j}(i)$ and $D_{j}(i)$ are the PV generated electricity and the load demand during the generic $i$-th time interval, respectively. Because not always $E_{P V, j}(i)$ fully covers $D_{j}(i)$ and the electricity supplied to the load never can surpass $D_{j}(i)$, the electricity $E_{P V l o a d, j}(i)$ that the PV system supplies to the load during the generic $i$-th time interval is

$E_{P V l o a d, j}(i)=\min \left[E_{P V, j}(i), D_{j}(i)\right]$

When the PV electricity and the electrical demand do not perfectly match each other, or the PV generation is insufficient, some amount of electricity is exchanged with the grid:

$E_{P V, j}(i)=E_{P V l o a d, j}(i)+E_{e x p, j}(i)$

$D_{j}(i)=E_{P V l o a d, j}(i)+E_{i m p, j}(i)$

where exported electricity $E_{\text {exp }, j}(i) \neq 0$, if $E_{P V, j}(i)>D_{j}(i)$; conversely imported electricity $E_{i m p, j}(i) \neq 0$, if $E_{P V, j}(i)<D_{j}(i)$. Obviously if

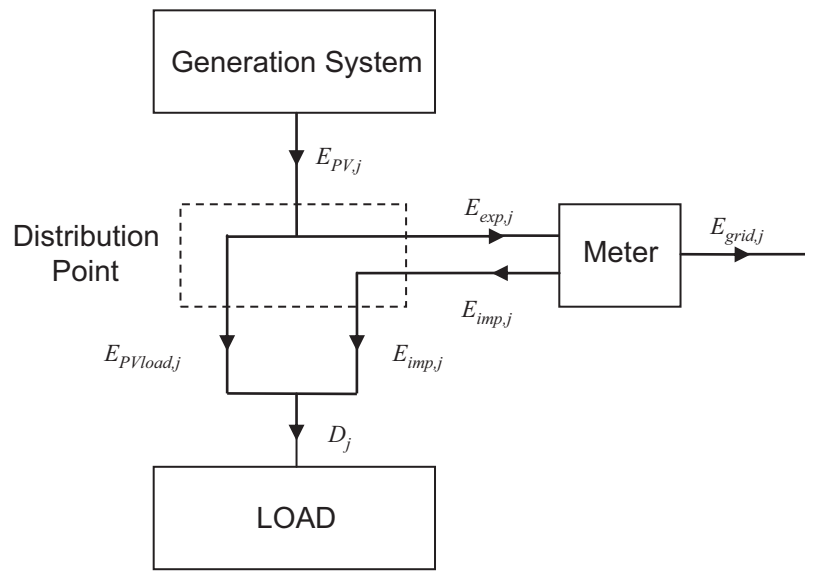

Fig. 11. Sketch of the energy exchanges in a PV systems without batteries.

$E_{\text {exp }, j}(i) \neq 0$ then $E_{i m p, j}(i)=0$, and vice versa, during the same time interval.

In order to consider the effect of the mismatch between generated and consumed electricity, many load matching indicators have been indicated. The ratio of the PV electricity provided to the users and the electrical demand was named the solar fraction by Widén et al. [10], the load match index by Voss et al. [19] and the cover factor by Verbruggen et al. [20]. Such a parameter, which represents the percentage of the electrical demand that is covered by the generation of the $j$-th PV system over the period, can be calculated with the following equation:

$\gamma_{D, j}=\frac{\sum_{i=1}^{N} \min \left[E_{P V, j}(i), D_{j}(i)\right]}{\sum_{i=1}^{N} D_{j}(i)} \cdot 100=\frac{E_{P V l o a d}^{*}, j}{*}$

where $N$ is the number of samples in the considered evaluation period. $E_{P V l o a d, j}^{*}$ and $D_{j}^{*}$ are the PV electricity provided to the users and the electrical demand of the $j$-th PV system over the evaluation period, respectively. The accurate evaluation of load match index $\gamma_{D, j}$ would require a dynamic approach based on the knowledge of the daily distribution of the electricity generation and demand. When only the yearly energy data are available, load match index $\gamma_{D}$ of the district may be evaluated with the approximate expression:

$\gamma_{D}=\frac{\sum_{j=1}^{N_{P V}} \min \left[E_{P V, j}^{*}, D_{j}^{*}\right]}{\sum_{j=1}^{N_{P V}} D_{j}^{*}} \cdot 100$

where it was assumed that:

$\sum_{j=1}^{N_{P V}} \sum_{i=1}^{N} \min \left[E_{P V, j}(i), D_{j}(i)\right] \approx \sum_{j=1}^{N_{P V}} \min \left[\sum_{i=1}^{N} E_{P V j}(i), \sum_{i=1}^{N} D_{j}(i)\right]=\sum_{j=1}^{N_{P V}} \min \left[E_{P V, j}^{*}, D_{j}^{*}\right]$

The above value of $\gamma_{D}$ was calculated with Eq. (2) that corresponds to the condition under which, if the PV generation is sufficient, the daily energy demand is always covered by the PV electricity. Such an optimistic condition is quite unreal because it involves a perfect simultaneity between PV generation and consumption. Actually, even adopting the best strategy to exploit the PV generation, the electricity $D_{\text {Night }}$ consumed after sunset and before dawn will be never compensated by the energy produced by a grid-connected PV system that does not use batteries. Therefore, to correctly assess the economic convenience, a minimum mismatch between generated and consumed electricity has to be always considered.

To calculate the value of $D_{\text {Night }}$, it was assumed that at least some appliances (lamps, refrigerator, television and P.C.) were working at night. Moreover, because the electricity generated by 
the PV systems is quite small at the beginning and at the end of the day, $D_{\text {Night }}$ was calculated from time $T_{i}$ and $T_{f}$ that correspond to one hour before sunset time and one hour after dawn time, respectively. Using the data officially available [21-24] and considering sunset and dawn time in Palermo on 15th of each month, it was calculated for a standard flat a value of $D_{N i g h t}$ equal to $716.5 \mathrm{kWh} /$ year; consequently the day energy demand $D_{\text {Day }}$ resulted equal to $5240.8 \mathrm{kWh} /$ year.

The portion of $D_{\text {Day }}$ that is matched by the PV electricity mainly depends on the habits of the households in using the electrical appliances. Some strategies, which are known as load management and demand side management, have been developed. Both strategies aim to enable the supply system to meet the demand in order to make the best use of its available generation and transmission capacity. Load management may be implemented by limiting the demand or shifting the consumption from peak to off-peak periods on a daily or weekly basis. Gellings et al. [25] described six load management strategies: (1) peak clipping, (2) valley filling, (3) load shifting, (4) strategic conservation, (5) strategic load growth and (6) flexible load shape. First three strategies aim to make the demand more constant in the time. Strategic conservation and strategic load deal with the improvement of the efficiency of energy use, the replacement of inefficient fossil fuel equipment and the raise of consumer productivity and quality of life. Flexible load shape assumes the use of specific contracts and tariffs along with consumers' equipment flexibly controlled.

All above strategies try to solve the problem from the point of view of the grid operators who are concerned about reducing to reduce the difference between the maximum and minimum values of the produced and dispatched electricity. Dealing with PV electricity the problem should be inverted because a very flat load curve represent the worst condition to efficiently utilize the PV generation that, by its very nature, is never constant. Actually, only if the consumption follows the variation of the PV generation, no surplus electricity - or the minimum - will be exported to the grid that, in turn, will be minimally perturbed by large-scale PV systems.

A household, aware of the importance of not wasting the electricity produced by its PV system, will implement simple and efficient personal strategies in using domestic appliances. Building automation can also provide economical solutions to manage the appliances with the highest consumption (washing machine, dishwasher, boiler) whose operation may be flexibly scheduled. Even smart control systems, able to forecast the solar potential and the PV generation up to 2 days, with hourly resolution, may be implemented [26].

Whatever are the strategies to reach the best load matching it is very difficult to calculate their real effects when the numerous PV systems installed on the roofs of a densely built city are analyzed. For this reason, in order to study the energy and economic impact of the load mismatch on the district load match index, a sensitivity analysis has been carried out on the basis of the available yearly energy data. To reach the purpose it is useful to split energy demand of the generic $j$-th PV system as described below:

$D_{j}^{*}=D_{\text {Day }, j}+D_{\text {Night }, j}=D_{M a t c h, j}+D_{M i s m, j}$

where $D_{\text {Match,j }}$ represents the amount of load matched demand and $D_{\text {Mism, } j}$ is the amount of mismatched demand. Let us assume that $D_{j}^{*}$ is constant $(5957.3 \mathrm{kWh} /$ year $)$ and that $D_{\text {Match }, j}$ varies from zero to $D_{\text {Day }, j}(5240.8 \mathrm{kWh} /$ year) as a consequence of the smart use of the electrical appliances:

$D_{\text {Match }, j}\left(c_{u}\right)=c_{u} D_{\text {Day }, j}$ where utilization coefficient $c_{u}$ :

$c_{u}=\frac{D_{\text {Match }, j}}{D_{\text {Day }, j}}$

varies from 0 (no PV generation used) to 1 (maximum PV generation used). Using Eq. (4) the yearly demand can be rewritten as

$D_{j}^{*}=D_{\text {Match }, j}\left(c_{u}\right)+D_{\text {Mism, }, j}\left(c_{u}\right)=E_{P V l o a d, j}^{*}\left(c_{u}\right)+E_{\text {imp }, j}^{*}\left(c_{u}\right)$

where $E_{i m p, j}^{*}\left(c_{u}\right)$ is the yearly imported electricity of the $j$-th PV system of the district and $E_{P V l o a d j}^{*}\left(c_{u}\right)$, which represents the PV electricity supplied to the matched demand $D_{M a c t h, j}\left(c_{u}\right)$, is calculated with the following expression:

$E_{P V l o a d, j}^{*}\left(c_{u}\right)=\min \left[E_{P V, j}^{*}, D_{M a t c h, j}\left(c_{u}\right)\right]=\min \left[E_{P V, j}^{*}, c_{u} D_{D a y}\right]$

By means of the above equations the load match index of the district can be can be related to utilization coefficient $c_{u}$ :

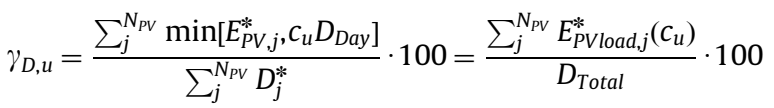

For given values of the electricity demand and PV generation, gross energy cover factor $C_{P V}$ is not affected by the load mismatch. Adversely, load match index $\gamma_{D, u}$ is sensitive to load mismatch and can be less than $100 \%$ for two different reasons. If the PV systems are undersized to cover the energy demands, then $E_{P V, j}^{*}<D_{j}^{*}$ and consequently $E_{P V l o a d, j}^{*}<D_{j}^{*}$. When the PV system is not undersized $\left(E_{P V, j}^{*}>D_{j}^{*}\right)$ but the generation mismatches the energy demand $\left(c_{u}<1\right)$, then $E_{P V l o a d, j}^{*}<D_{j}^{*}$. Even though the PV production perfectly covers the demand $\left(E_{P V, j}^{*}=D_{j}^{*} \rightarrow C_{P V}=100 \%\right.$ ), when $c_{u}<1$, some amount of energy produced $E_{P V, j}^{*}$ is not contemporary consumed and consequently it is $\gamma_{D, u}<100 \%$. In a gridconnected PV system, which does not use batteries, both the lack of solar radiation and the inadequate use the appliances affect the load match index. The difference between the gross energy cover factor and the load match index indicates the percentage ratio of the PV generation exported to the grid to the electricity demand.

\section{Results}

Prior to calculating the effect of the load mismatch on the coverage of the electricity demand of the district, it is interesting to observe how the energy and economic performances of the PV systems change with the types of roof on which are installed. For the sake of brevity only the results related to few types of roofs, chosen to represent the various roofing technologies, are presented. For each type of roof the PV systems with the highest energy performances are reviewed. If it is not differently declared, the graphs of this section do not consider the shadowing effect of obstructions.

\subsection{Gable roof type $T 2$ and $T 3$ analysis}

Gable roofs types T1 and T2 are very common in the analyzed district. Type T1 roofs cover $13.16 \%$ of all buildings and produces $14.42 \%$ of the total electricity generated by the PV systems installable on all the district's roofs. Fig. 12 depicts some figures of the electricity demand coverage that were calculated assuming the most optimistic conditions in which a perfect load matching $\left(c_{u}=1\right)$ is present.

The PV systems installed on buildings of one or two floors are oversized because the gross energy cover factor surpasses the value of $88.0 \%$ corresponding to the ratio of $D_{\text {Day }}$ to the daily total demand. The gross load match index, which corresponds to the gross energy cover factor when a PV system is not oversized, is 
$98.3 \%$ of $D_{\text {Day }}$ for a building with three floors; the load coverage lowers to $19.7 \%$ of $D_{\text {Day }}$ for a building with nine floors.

Fig. 13 shows the ratio of the net present value to the present value of costs of the PV system (NPV/PVC), which is a parameter useful to assess the economic convenience of a PV system. If the $\mathrm{NPV} / \mathrm{PVC}$ is positive, then the revenues surpass the disbursements over the PV system lifetime and the investment will be profitable; with a NPV/PVC of $10 \%$, if the disbursements are 100 , the revenues will be 110 . The opposite is for negative values of NPV/PVC. Moreover, high values of NPV/PVC indicate that payback period will be quite short. Adversely, a NPV/PVC near to zero represents a critical situation where the results of the economic analysis may be abruptly upturned by small variations in the assessment of costs and benefits.

The filtered load match indexes of the PV systems installed on buildings of one and nine floors are zero because, as it is possible to deduce observing Fig. 13, these systems are always economically disadvantageous. The reasons are different. The PV systems referred to one floor are not convenient because the cost of the oversized PV fields is exorbitant compared to the revenues of selling the surplus energy exported to the grid. Adversely, due to the lack of incentives, which are not paid when the peak power is less than $1 \mathrm{~kW}$, the investment for PV systems installed on buildings of nine floors cannot be recouped.

Coefficient $c_{u}$, which indicates how much the electricity demand from dawn to dusk is covered by the PV generation,

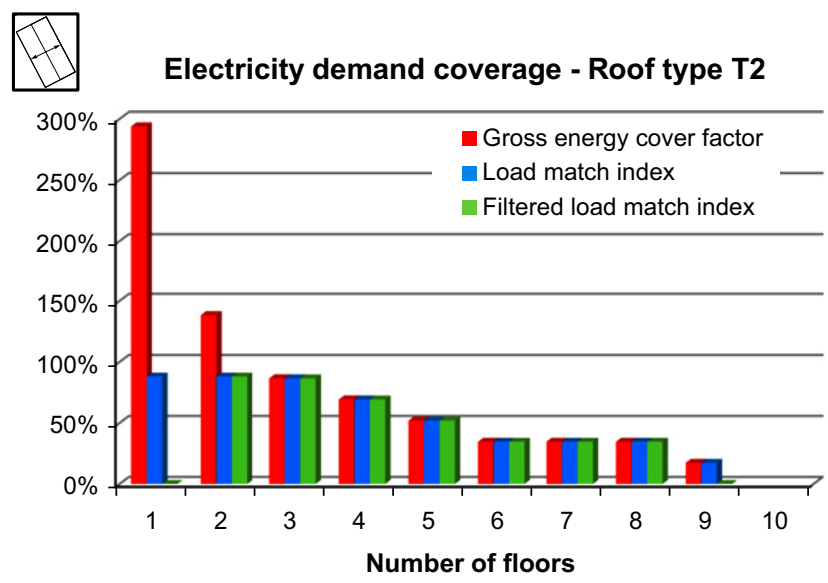

Fig. 12. Roof type $\mathrm{T} 2$ figures of the electricity demand coverage versus the number of floors $\left(c_{u}=1\right)$.

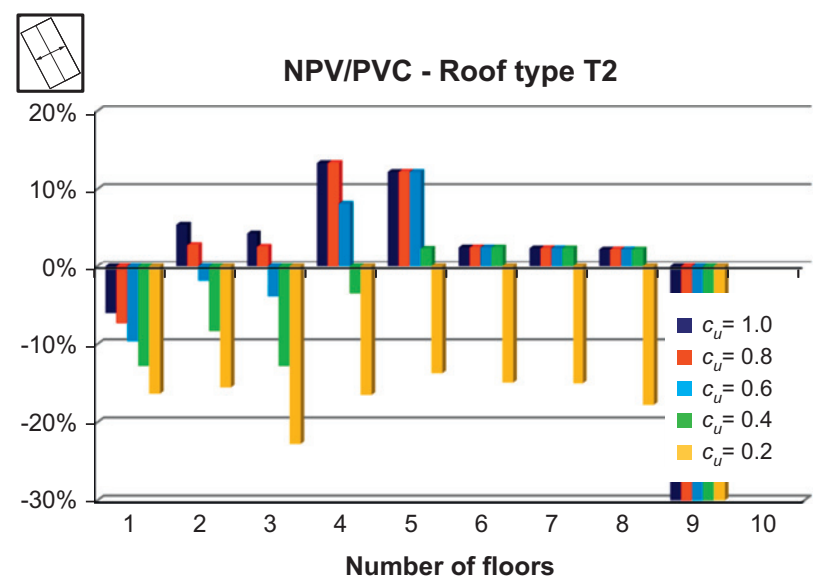

Fig. 13. Ratio of the net present value to the present value of costs for a roof type $\mathrm{T} 2 \mathrm{PV}$ system versus the number of floors. significantly affects the value of the filtered load match index. It can be observed that the PV systems installed on buildings of two and three floors are economically advantageous if $80 \%$ of the demand matches the PV generation. PV systems installed on fourfloor buildings requires that $60 \%$ of the demand is matched. A greater flexibility, which allows a load matching of $40 \%$, is shown by the PV systems installed on the buildings with a number of floors greater than four. No PV systems will be economically convenient when only $20 \%$ of the demand is covered by the PV electricity.

Gable roofs types T3, T4, T4 and T5 are present in the analyzed district with almost the same percentage. Type T3 roofs cover $2.74 \%$ of all buildings and produces $2.91 \%$ of the PV electricity generated by all the installable PV systems.

Observing Fig. 14 it is easy to recognize that the PV systems installed on buildings of one or two floors are oversized. A PV system installed on a building with three floors covers $90.7 \%$ of $D_{\text {Day }}$; the coverage lowers to $30.2 \%$ of $D_{\text {Day }}$ for buildings with more than six floors.

The PV systems installed on buildings of one floor are economically disadvantageous due to the cost of the oversized PV fields. Adversely, because the advantages for the reduced cost for the electricity bills are quite marginal, the PV systems installed on buildings of more of six floors do not compensate the investment.

Fig. 15 shows that the PV systems installed on buildings of two and three floors are economically advantageous if $80 \%$ of the demand matches the PV generation. For the PV systems installed on buildings with four, five and six floors it is sufficient that $40 \%$ of the demand is matched. No PV systems will be economically convenient when only $20 \%$ of the demand is covered by the PV electricity.

Because $65.67 \%$ of type T2 and $69.78 \%$ of type T3 refer to roofs belonging to buildings of four, five and six floors, this kind of roofing can be very effective to cover the energy demand of the district even with values of load matching that are not optimal.

\subsection{Hip roof type T8 analysis}

Due to their shape, on the hip roofs types T7 and T8a smaller number of PV panels can be generally located. Type T8 roofs cover $2.94 \%$ of all buildings and produces $2.93 \%$ of the PV electricity generated by all the installable PV systems of the district. The side angle, which is the tilt of the triangular portions of and hip roof [27], affects the PV energy generation. An hip roof type T8, with a side angle of $25^{\circ}$ and a tilt angle of $25^{\circ}$, generates less electricity

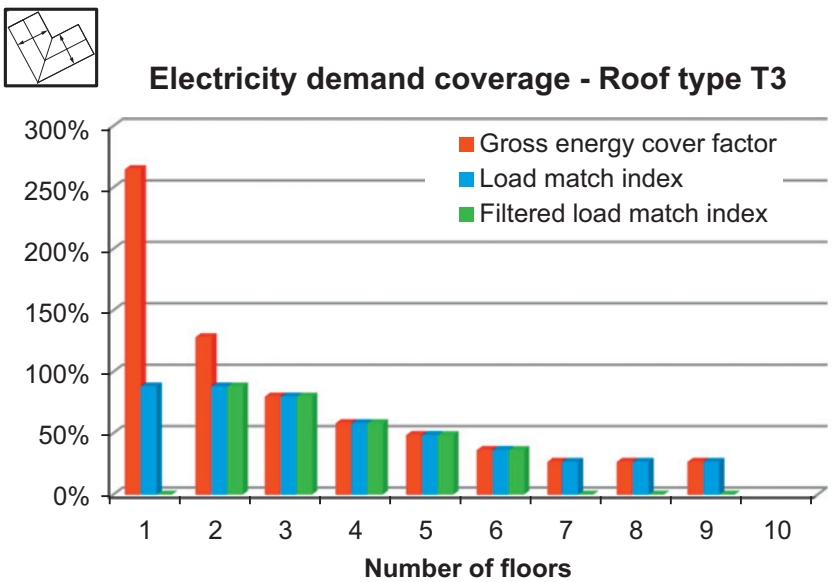

Fig. 14. Roof type $\mathrm{T} 3$ figures of the electricity demand coverage versus the number of floors $\left(c_{u}=1\right)$. 


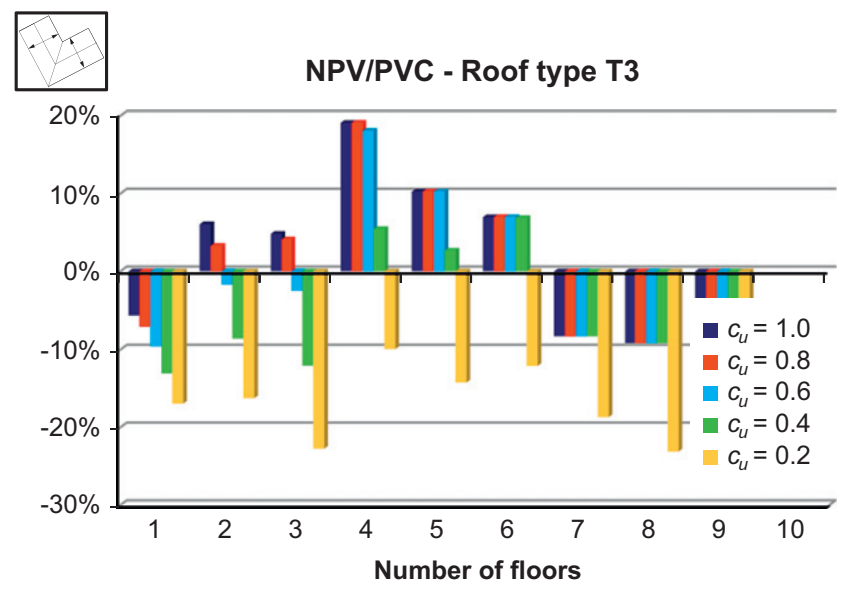

Fig. 15. Ratio of the net present value to the present value of costs for a roof type T3 PV system versus the number of floors.

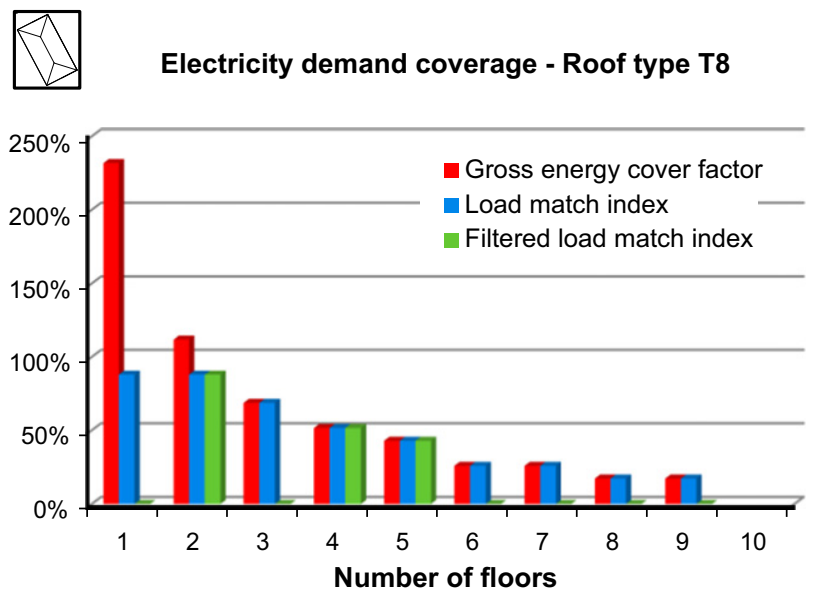

Fig. 16. Roof type T8 figures of the electricity demand coverage versus the number of floors $\left(c_{u}=1\right)$.

than a gable roof type $\mathrm{T} 2$ that has the same tilt angle; actually, hip roof type T8 produces $79 \%$ of the electricity generated by T2.

As it is shown in Fig. 16 the PV systems installed on buildings of one or two floors are oversized; a PV system installed on a building with three floors covers $78.3 \%$ of $D_{\text {Day }}$. The coverage lowers to $19.7 \%$ of $D_{D a y}$ for buildings with more than seven floors.

The filtered load match indexes of PV systems installed on buildings of one floor are economically disadvantageous due to the cost of the oversized PV fields. Adversely, because the advantages for the reduced costs for the electricity bill are quite marginal, PV systems installed on buildings of more than five floors do not recoup the investment.

In Fig. 17 it is easy to observe that coefficient $c_{u}$ irregularly affects the value of the filtered load match index for a number of floors included between two and five. The PV systems installed on buildings of two floors are economically advantageous if $80 \%$ of the demand matches the PV generation. The PV systems located on buildings of three floors are never profitable. For the PV systems installed on buildings with four floors it is sufficient that $40 \%$ of the demand is matched, whereas a load matching of $60 \%$ is required for five floors. Again, no PV systems will be economically convenient when only $20 \%$ of the demand is covered by the PV electricity.

Roof type T8 is very sensitive to the economic assessment. For $c_{u}=1$ and three floors, it is NPV/PVC $=-0.98 \%$, which indicates

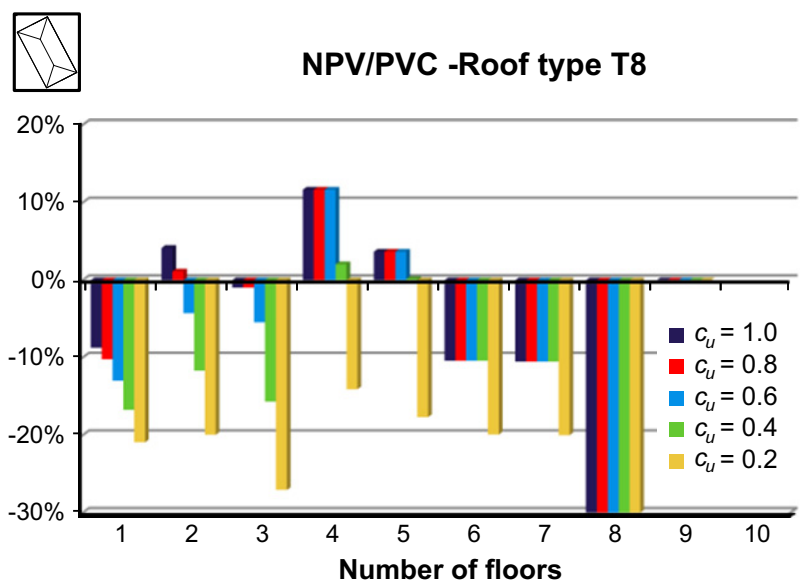

Fig. 17. Ratio of the net present value to the present value of costs for a roof type T8 PV system versus the number of floors.

that the energy assessment is very critical because a difference in the costs or benefits of few hundreds of euros may invert the judgement about the profitability of the investment.

\subsection{Skillion roof type $T 9$ and $T 13$ analysis}

Skillion roofs types T9, T10, T11 and T12 allow the placement of the greatest number of PV panels. For this reason the PV systems installed on skillion roofs are very energy effective. Type T9 roofs cover $2.34 \%$ of all buildings and produces $5.11 \%$ of the PV electricity generated by all PV systems of the district. The different and less advantageous orientation of roofs types T10, T11 and T12 determines a reduction of electricity production [28]. The rotation of $180^{\circ}, 90^{\circ}$ and $-90^{\circ}$ from the optimally oriented roof type T9, which corresponds to roof types T10, T11 and T12, respectively produces a reduction of $32 \%, 16 \%$ and $19 \%$ in the electrical generation.

Fig. 18 shows that the PV systems located on buildings with less than five floors are oversized. A PV system installed on a building with five floors is able to cover $95.7 \%$ of $D_{\text {Day }}$; the gross load match index lowers to $50.7 \%$ of $D_{\text {Day }}$ for a building with nine floors.

The filtered load match index of PV systems installed on buildings of one floor is zero because these systems are economically disadvantageous. Thanks to the paid incentives, which are very high due to the great value of the generated PV electricity, the PV systems are economically advantageous for each number of floors greater than one, even if they are oversized. The NPV/PVC may surpass 30\% and for this reason the pay-back period results shorter than ten years.

Fig. 19 shows that PV systems installed on two-floor buildings requires that $80 \%$ of the demand is matched. The profitability of the PV systems located on building of three and four floors is reached if $60 \%$ of the demand is matched. A greater flexibility, which allows a load matching of $40 \%$, is shown by the PV systems installed on the buildings with a number of floors greater than four. No PV systems will be economically convenient when only $20 \%$ of the demand is covered by the PV electricity.

Even skillion roofs types T13, T14, T15 and T16, which are quite frequent in the analyzed district, result very energy effective. Type T13 roofs cover $3.86 \%$ of all buildings and produces $5.91 \%$ of the PV electricity generated by all the installable PV systems.

Observing Fig. 20 it is easy to recognize that the PV systems installed on buildings of less of four floors are oversized; a PV 
Electricity demand coverage - Roof type T9

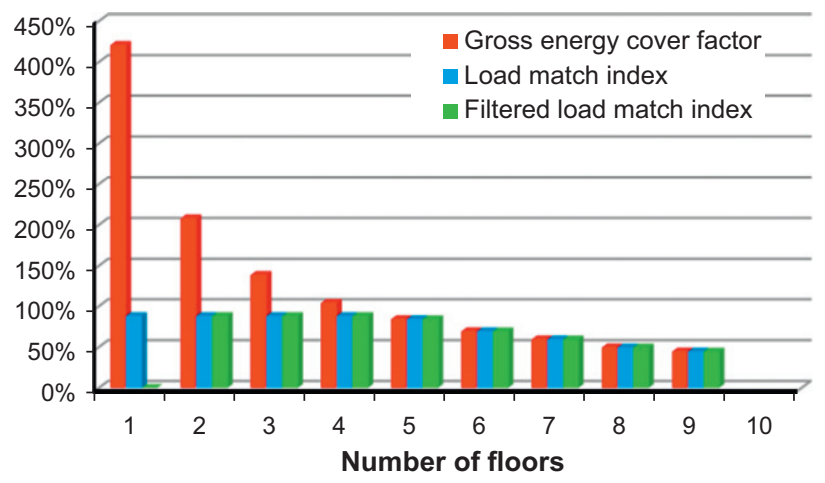

Fig. 18. Roof type T9 figures of the electricity demand coverage versus the number of floors $\left(c_{u}=1\right)$.

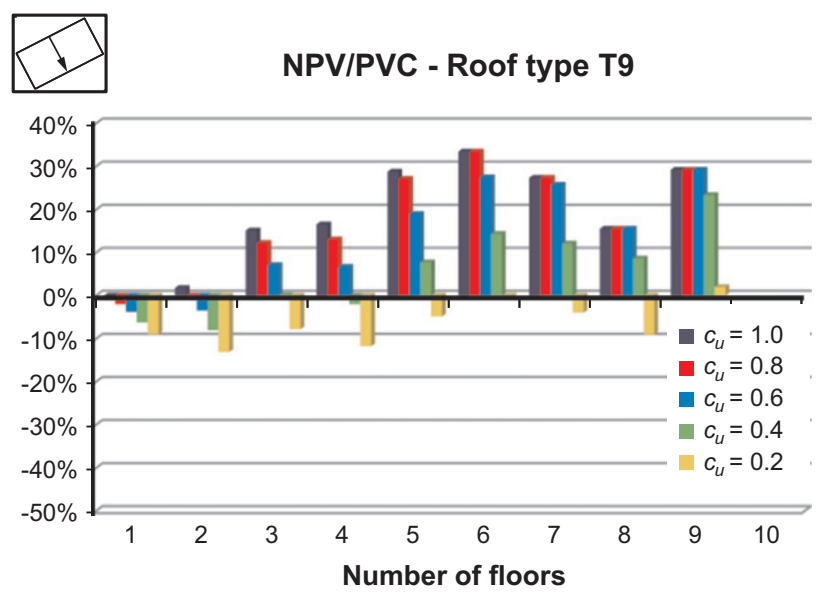

Fig. 19. Ratio of the net present value to the present value of costs for a roof type T9 PV system versus the number of floors.

system located on a building with three floors covers $98.2 \%$ of $D_{\text {Day }}$. The coverage lowers to $43.2 \%$ of $D_{\text {Day }}$ for buildings with more than seven floors.

Although they are oversized, the PV systems installed on buildings of less than four floors are economically advantageous. The calculated pay-back period of PV systems located on buildings with five or six floors may result quite short because are about eight years.

Fig. 21 shows that the PV systems installed on buildings of one, three and four floors are economically advantageous if $60 \%$ of the demand matches the PV generation. For the other PV systems it is sufficient that $40 \%$ of the demand is matched. No PV systems will be economically convenient when only $20 \%$ of the demand is covered by the PV electricity.

\subsection{Flat roof type FR5 and FR1 analysis}

Roofs Type FR5, which indicates the class of flat roofs with the widest roofing areas, covers $16.15 \%$ of all buildings. The PV systems, which are considered to be oriented to the South with a tilt angle of $30^{\circ}$, produce $11.34 \%$ of the PV electricity generated by all PV systems of the district.

Observing Fig. 22 it is easy to recognize that the PV systems located on buildings with less than three floors are oversized. A PV system installed on a building with three floors is able to cover

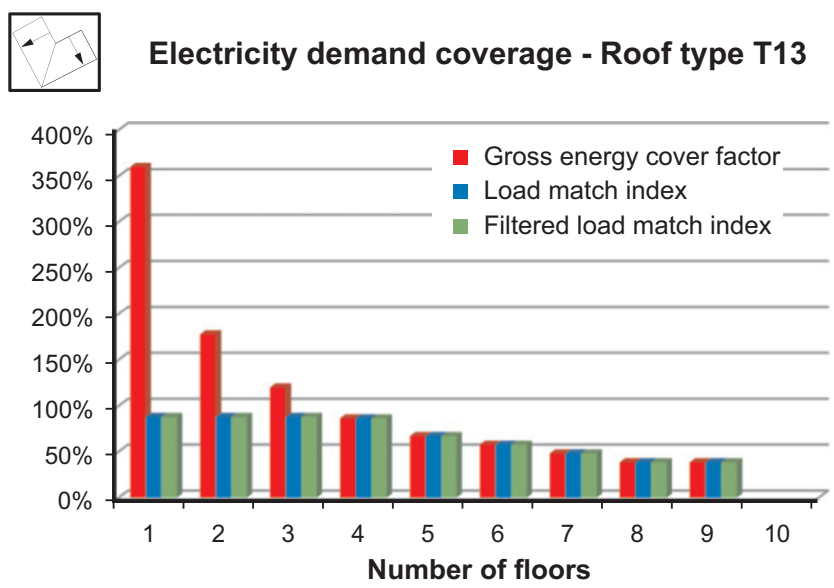

Fig. 20. Roof type T13 figures of the electricity demand coverage versus the number of floors $\left(c_{u}=1\right)$.

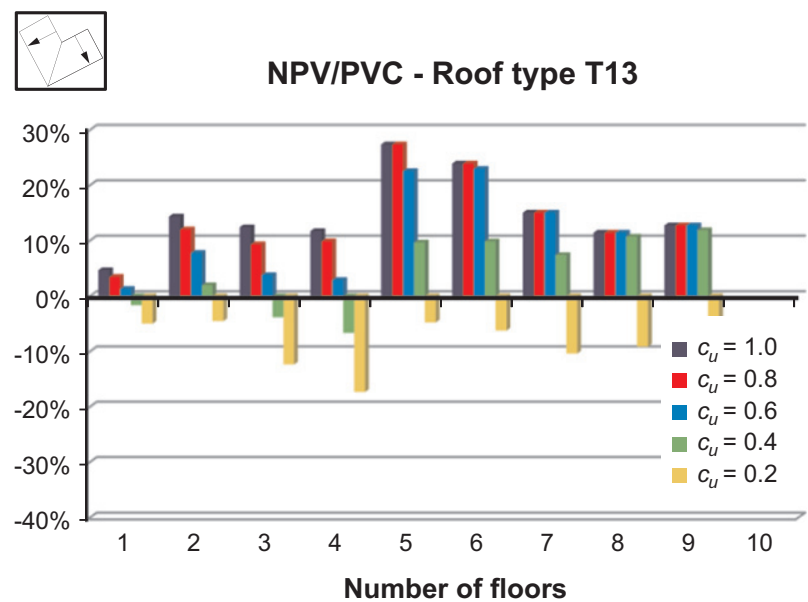

Fig. 21. Ratio of the net present value to the present value of costs for a roof type T13 PV system versus the number of floors.

$92.0 \%$ of $D_{\text {Day }}$; the gross load match index lowers to $27.7 \%$ of $D_{\text {Day }}$ for a building with ten floors.

Fig. 23 shows that the filtered load match index is zero only for PV systems installed on buildings with more than nine floors. NPV/PVC reaches very high values and the pay-back period may also result smaller than eight years. This type of roof presents a small sensitivity to the load mismatch because if only $20 \%$ of the demand is covered, the investment results profitable. Such a performance is mainly due to the possibility of placing a great number of PV panels because the unavailable portions of roof are relatively small due to the wide dimension of the buildings.

For roof type FR1, which represents the class of flat roofs with the smallest roofing areas, the energy and economic performances are a bit different. Roofs Type FR1 covers 3.13\% of all buildings and produces $1.33 \%$ of the PV electricity generated by all PV systems of the district.

Fig. 24 depicts some figures of the electricity demand coverage. A PV system located on a building with three floors covers $72.8 \%$ of $D_{\text {Day }}$; the coverage lowers to $14.6 \%$ of $D_{\text {Day }}$ for a building with five floors. Fig. 25 shows that the pay-back period of PV systems located on buildings with less than four floors may result quite short.

Fig. 25 also shows that the PV systems installed on buildings with more than five floors are always economically disadvantageous. For the other buildings this type of roof presents a small 


\section{Electricity demand coverage - Roof type FR5}

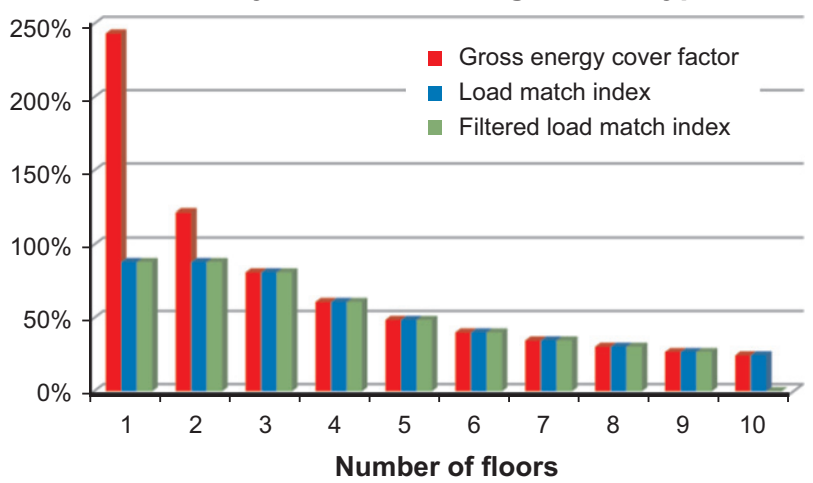

Fig. 22. Roof type FR5 figures of the electricity demand coverage versus the number of floors $\left(c_{u}=1\right)$.

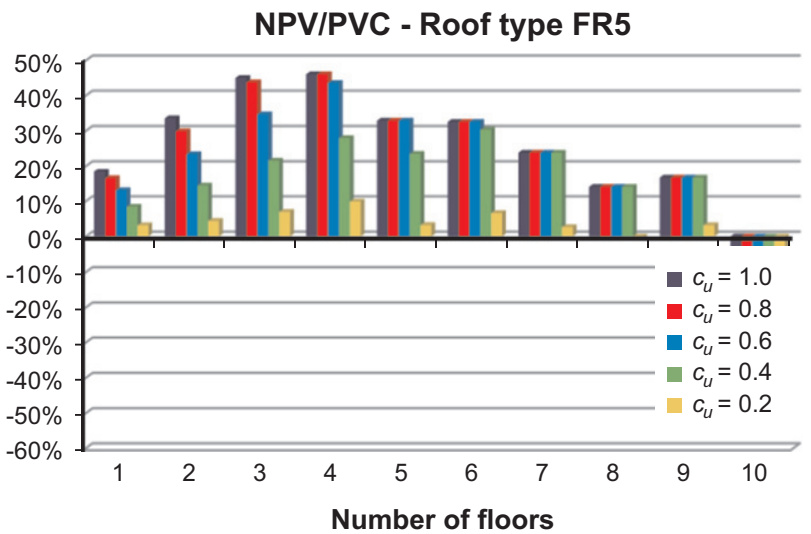

Fig. 23. Ratio of the net present value to the present value of costs for a roof type FR5 PV system versus the number of floors.

\section{Electricity demand coverage - Roof type FR1}

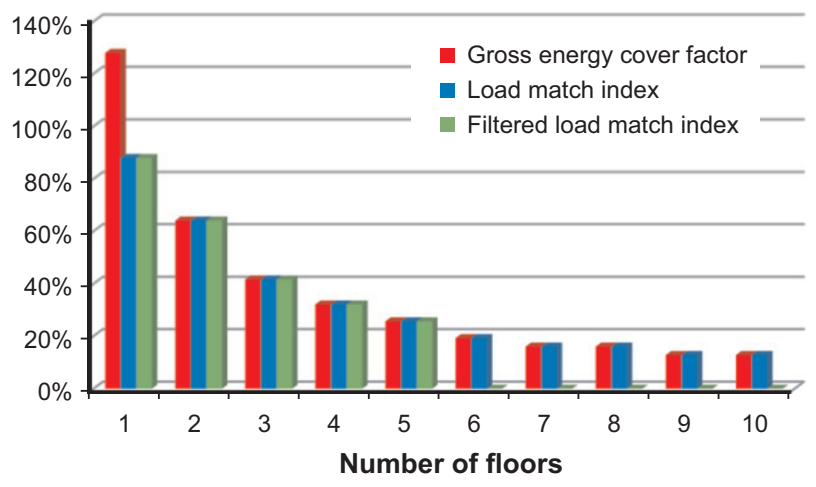

Fig. 24. Roof type FR1 figures of the electricity demand coverage versus the number of floors $\left(c_{u}=1\right)$.

sensitivity to the load mismatch because if only $20 \%$ of the demand is covered, the investment results profitable.

The main difference between roof type FR1 and FR2 consists in the fact that type FR1 is more suited for PV systems installed on low buildings, whereas the opposite is true for type roof FR5. This assertion is confirmed by the graphs related to the other flat roofs FR2, FR3 and FR4, not presented for the sake of brevity, that show a regular transition of the energy and economic performances.
NPV/PVC - Roof type FR1

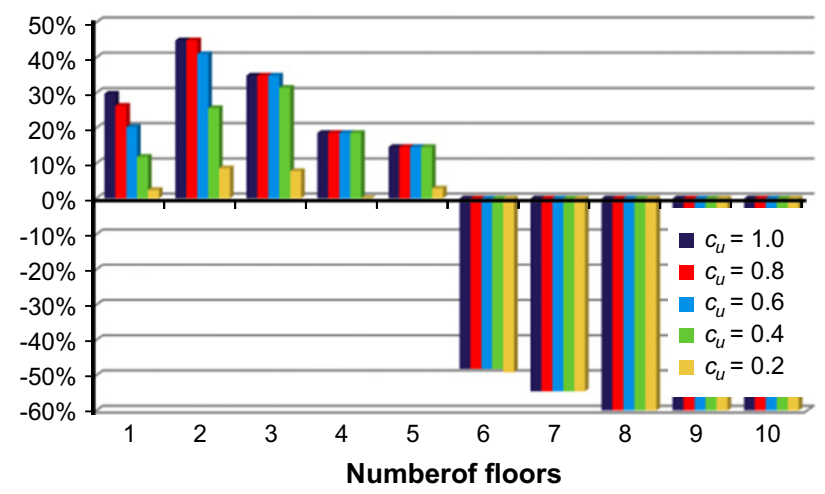

Fig. 25. Ratio of the net present value to the present value of costs for a roof type FR1 PV system versus the number of floors.

\section{Load match indexes $\gamma_{D}$ for the whole district}

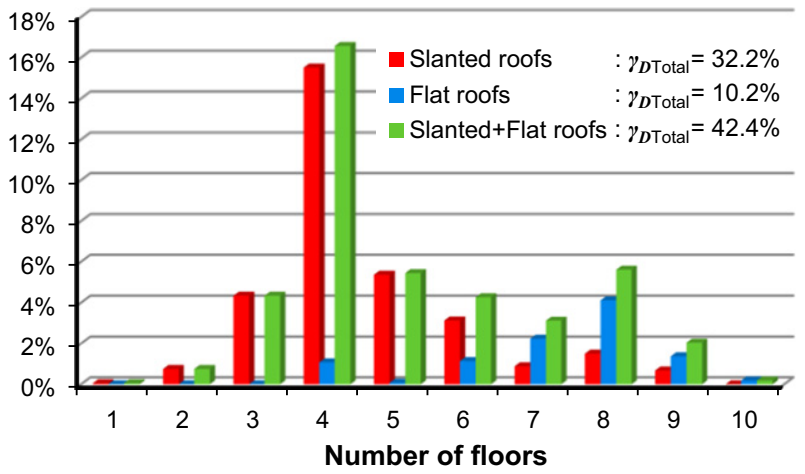

Fig. 26. Yearly load match indexes for the whole district, versus the number of floors $\left(c_{u}=1\right)$.

\subsection{Overall analysis of the district}

In Fig. 26 the yearly load match indexes of the district are shown. Without any shading effect due to surroundings, the PV electricity supplied to the load is $42.4 \%$ of the district demand.

Comparing Fig. 26 to Fig. 9, it can be observed that the difference between the gross energy cover factor and load match index corresponds to $1.5 \%$ of the district demand; this amount of electricity, which is exported to the grid, is due to the PV systems installed on the roofs of the lowest buildings that are more likely to result oversized. Their effect is quite small because the roofs of buildings with one, two and three floors represent less than $9 \%$ of the total roofing surface of the district.

Fig. 27 depicts the values of the load match indexes filtered considering the results of the economic assessment of the PV systems profitability. The value of $42.4 \%$ lowers to $30.2 \%$, with a percentage decrement of $29 \%$. The overall effect of the load mismatch, which variously affects each kind of roof types, is shown in Fig. 28, where the load match indexes are depicted versus the number of floor for some values of utilization coefficient $c_{u}$.

If $c_{u}$ varies from 1 to 0.8 , the load mismatch lowers the load match index of the district from $42.4 \%$ to $40.5 \%$, with a relative reduction to $95.5 \%$ of the initial value; if $c_{u}$ is 0.2 the load match index reaches the value of $15.8 \%$, with a relative reduction to $37.1 \%$.

The effect, which is not linearly proportional, is more evident in Fig. 29 that depicts the filtered load match indexes versus the number of floor for some values of utilization coefficient $c_{u}$. In this 
Filtered Load match indexes $\gamma_{D}$ for the whole district

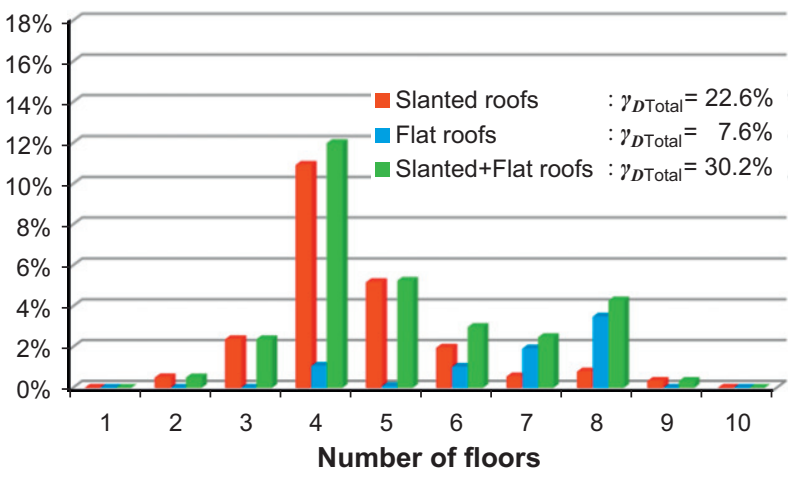

Fig. 27. Yearly load match indexes for the whole district, filtered by the economic assessment, versus the number of floors $\left(c_{u}=1\right)$.

\section{Load match indexes $\gamma_{D}$ for the whole district}

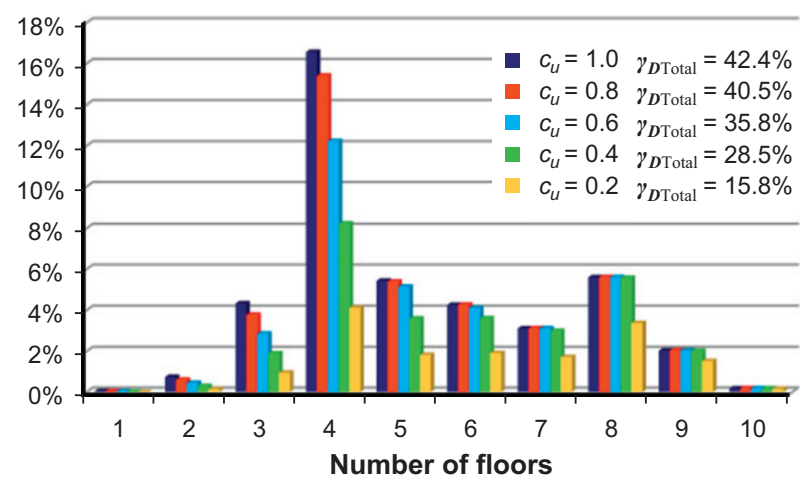

Fig. 28. Yearly load match indexes for the whole district versus the number of floors.

Filtered load match indexes $\gamma_{D}$ for the whole district

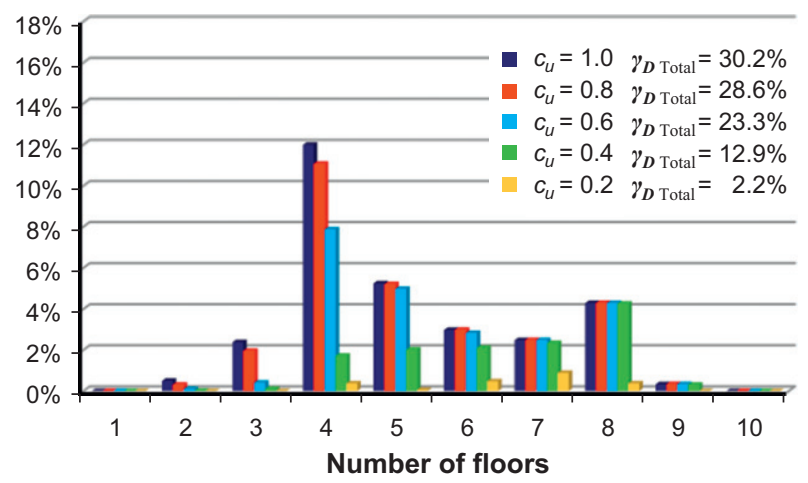

Fig. 29. Yearly load match indexes for the whole district, filtered by the economic assessment, versus the number of floors.

case when $c_{u}$ varies from 1 to 0.8 , the filtered match index changes from $30.2 \%$ to $28.6 \%$, with a relative reduction to $94.7 \%$ of the initial value; the filtered load match index lowers to $2.2 \%$, with a relative reduction to $7.1 \%$, when $c_{u}=0.2$.

Fig. 30 shows the effect of utilization coefficient $c_{u}$ on the filtered gross energy cover factor of the district for different values of the shading coefficient varying from zero (no shading) to $100 \%$ (no solar energy).

As it was expected, all PV systems become economically ineffective when only a very small amount of the electricity demand is covered by the PV generation. Adversely, when the
Filtered gross energy cover factor $C_{P V}$ for the whole district

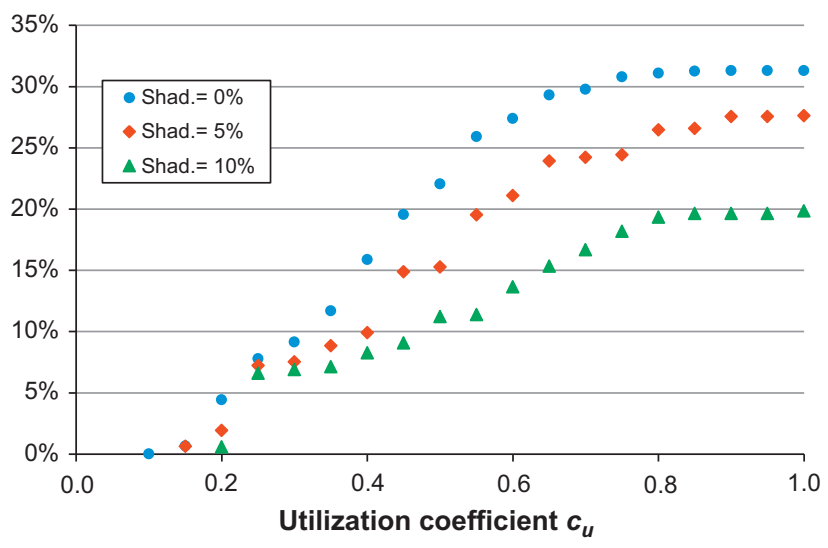

Fig. 30. Yearly gross energy cover factors for the whole district, filtered by the economic assessment, at various values of the shading coefficient versus utilization coefficient $c_{u}$

\section{Load match index $\gamma_{D}$ for the whole district}

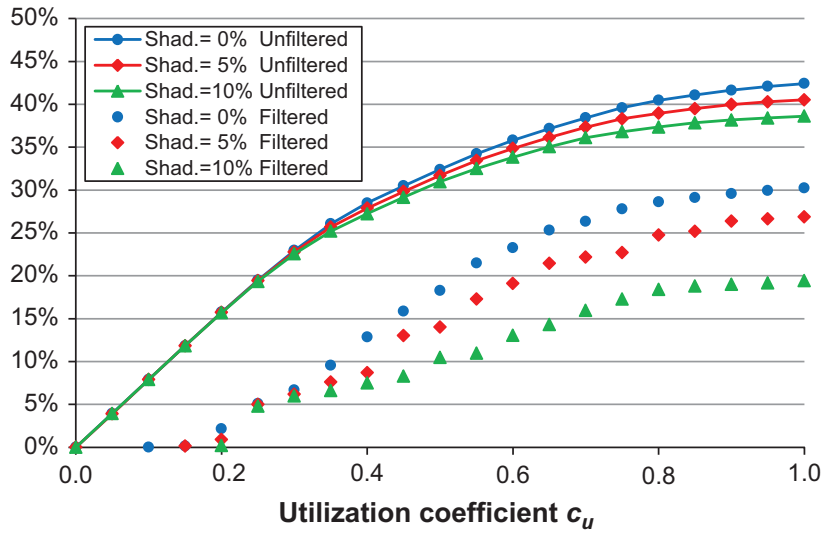

Fig. 31. Yearly load match index for the whole district (with economically filtered and unfiltered data) at various values of the shading coefficient versus utilization coefficient $c_{u}$.

shadowing coefficient is zero, the load mismatch has a little effect on the gross energy cover factor if more than $60 \%$ of the electricity demand is covered by the PV generation. For values of $c_{u}$ less than $60 \%$ an abrupt abatement of $C_{P V}$ is observed; this abatement appears for $c_{u}$ less than $80 \%$ when $10 \%$ of the energy is shaded. The value of $17 \%$, fixed in Europe for the share of energy from renewable sources in gross final consumption of energy in 2020 , can be reached with a utilization coefficient greater than $42 \%$, with a zero shadowing, and greater than $52 \%$ when a shadowing coefficient of $5 \%$ is considered. In Fig. 31 the variation of load match index $\gamma_{D}$ is shown.

If the unfiltered values of PV generation are considered, $\gamma_{D}$ gradually decreases with utilization coefficient $c_{u}$ and its reduction is also linearly proportional to the shadowing coefficient. Load match index, which is $42.4 \%$ if no shadowing effect is considered, lowers to $38.6 \%$ with a shadowing coefficient of $10 \%$.

The linear proportionality with the shadowing coefficient is not kept when the filtered values of PV generation are considered. The filtered load match index is $30.2 \%$ if no shadowing effect is considered; it lowers to $19.4 \%$ with a shadowing coefficient of $10 \%$. The value of $17 \%$ of $\gamma_{D}$ is reached with a utilization coefficient greater than $48 \%$ with a zero shadowing and greater than $55 \%$ when a shadowing coefficient of $5 \%$ is considered. Fig. 32 shows 


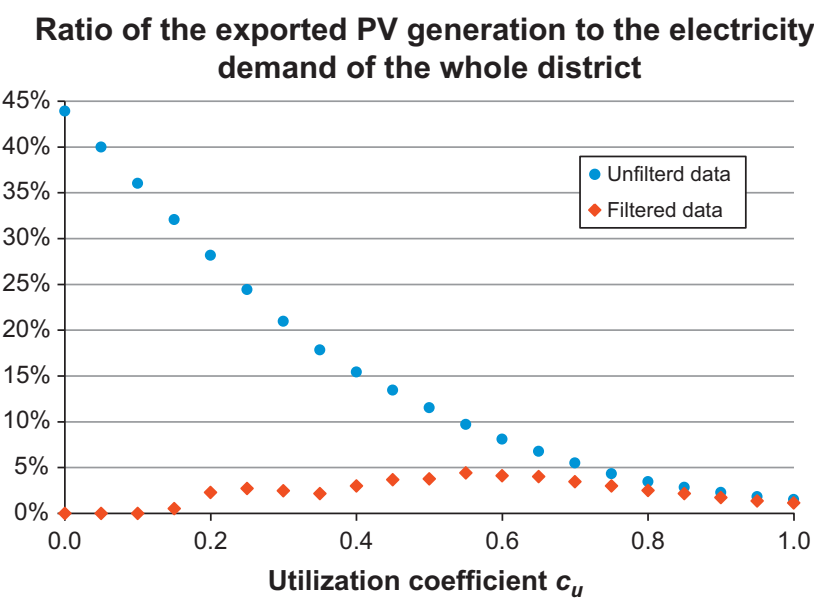

Fig. 32. Ratio of the PV electricity exported to the grid to the energy (with economically filtered and unfiltered data) versus utilization coefficient $c_{u}$.

the difference between the gross energy cover factor and the load match index, calculated with no shadowing effect; such a difference indicates the ratio of the PV electricity exported to the energy demand of the district.

If the PV generation and the energy supplied to the load are calculated without considering the effect of the economic analysis, the amount of PV electricity exported to the grid regularly varies with the utilization coefficient. With no load mismatch $\left(c_{u}=1\right)$, almost all PV generation is used to supply the load; only a very small amount of PV electricity (1.5\% of the demand), which corresponds to the PV systems that produce more than the demand, is exported to the grid. If the load is completely mismatched the fully PV generation (43.9\% of the demand) is exported to the grid. This amount of exported PV electricity corresponds to the hypothetical situation in which all the roofs of the district were used to install PV systems, without considering their economic viability and all the PV electricity were exported. The random injection into the grid of $43.9 \%$ of the demand would require a high capability of the grid to quickly reduce of the same amount the dispatched electricity. The curve of Fig. 32 referred to the filtered data shows that this event, which may worry the grid operator, should be impossible in these conditions because no PV system would have passed the economic assessment and, consequently, no homeowner would have installed it.

Dealing with more realistic situations, with a load mismatch of $60 \%\left(c_{u}=0.4\right)$ the PV systems would export $15.4 \%$ of the demand, but only $3 \%$ of the demand would be injected into the grid by the PV systems whose profitability was verified. Because the householders are interested in making their PV systems profitable, it is sensible to think that the PV electricity exported to the grid will be similar to the values depicted in Fig. 32 using the filtered data.

Nevertheless, because load mismatch values varying from $40 \%$ to $60 \%$ are not uncommon occurrences, smart habits should be adopted in using household appliances and modern building automation systems might be installed to better harness the PV electricity. Contrary the large PV generation plants, which it is reasonable to think that will be built in zones far from a city, the PV systems installed in dense urban areas should not represent a worry to the grid operators.

\section{Conclusions}

The evaluation of the real energy and economic effectiveness of the PV systems for reaching ambitious targets of the European
Union in the energy field is of paramount importance for addressing decision makers towards different options of financial support.

In the meantime scientists have developed much experience but still now it misses a simple methodology for assessing the effectiveness of the PV systems in urban contexts, where the complexity of the problem has to cope with the need to simulate PV systems in a reliable, fast and effective way. A methodological approach, which has the above requested features and permits to test the level of integration of the photovoltaic technology in urban areas, was used to analyze a district of the city of Palermo (Italy) in order to assess the coverage of the electricity demand and the economic feasibility of grid-connected photovoltaic systems installed on the roofs of multi-storey buildings. The roofs were classified according to the shape, orientation and pitch of buildings with different morphologies by means of satellite images provided by Google Earth ${ }^{\mathrm{TM}}$ and the share of energy generated by the installable PV systems was evaluated with regard to the number of floors.

The load match index of the whole district resulted $42.4 \%$ if no shadowing effect is considered; it lowers to $38.6 \%$ assuming that $10 \%$ of the solar radiation is obstructed by the surroundings. The above values are sensibly reduced when the results of the economic assessment are considered. A maximum value of $30.2 \%$ was reached; with a shading of $10 \%$ a load match index of $19.4 \%$ is obtained. The non-linearity of the decrement, which is due to the effect of the economic assessment, is quite evident.

The study has shown the significant effect of the load mismatch and the consequent impact on the economic convenience of investments. PV systems installed on various types of roof were analyzed in order to observe the effect of the oversized PV fields and of utilization coefficient $c_{u}$, which indicates how much the electricity demand from dawn to dusk is covered by the PV generation.

Oversizing the PV fields almost always makes the PV systems unprofitable. Gable roofs resulted very convenient when the PV systems are installed on the roofs of buildings with four and five floors. Hip roofs showed a high sensitivity to coefficient $c_{u}$. Skillion roofs, which are very energy effective, tolerate a load matching of $40 \%$ when the PV systems are installed on the buildings with a number of floors greater than four. The convenience of the PV systems located on flat roofs depends on the relation between the roof area and the number of floors of the building. To be convenient, the size of the flat roof has to increase with the number of floors of the building. The PV systems installed on flat roofs resulted almost insensitive to the load mismatch because they also accept a value of $c_{u}$ equal to 0.2 .

The reduction in the cost for the purchased electricity and the profit for the sold surplus energy, which depend on the load mismatch, strongly affect the economic convenience of PV systems. The feed-in tariff policy adopted by Italy incorrectly does not consider the load mismatch and incentives the whole energy generation even if the electricity produced is not consumed by the producer. Actually, such a feed-in tariff policy cause counterproductive effects: PV systems installed on some types of floor may result economically advantageous for a householder but represent a problem for the grid operators due to the random injection into the grid of PV electricity that does not match the consumption. The study has shown that the worries of the traditional electricity producers and dispatchers may be exaggerated because the penetration of PV systems is significantly limited by their economic viability.

\section{References}

[1] Paatero JV, Lund PD. Effects of large-scale photovoltaic power integration on electricity distribution networks. Renewable Energy 2007;32:216-34. 
[2] Denholm P, Margolis RM. Evaluating the limits of solar photovoltaics (PV) in traditional electric power systems. Energy Policy 2007;35:2852-61.

[3] Denholm P, Margolis RM. Evaluating the limits of solar photovoltaics (PV) in electric power systems utilizing energy storage and other enabling technologies. Energy Policy 2007;35:4424-33.

[4] Stodola N, Modi V. Penetration of solar power without storage. Energy Policy 2009;37:4730-6.

[5] Passey RJ, Watt ME, Snow M, Outhred HR, Spooner T. Study of grid-connected photovoltaic systems: benefits, opportunities and strategies. Progress in Photovoltaics: Research and Applications 2009;17:419-31.

[6] Solomon AA, Faiman D, Meron G. An energy-based evaluation of the matching possibilities of very large photovoltaic plants to the electricity grid: Israel as a case study. Energy Policy 2010;38:5457-68.

[7] Solomon AA, Faiman D, Meron G. The effects on grid matching and ramping requirements, of single and distributed PV systems employing various fixed and sun-tracking technologies. Energy Policy 2010;38:5469-81.

[8] Solomon AA, Faiman D, Meron G. Appropriate storage for high-penetration gri-connected photovoltaic plants. Energy Policy 2012;40:335-44.

[9] Myers KS, Klein SA, Reindl DT. Assessment of high penetration of solar photovoltaics in Wisconsin. Energy Policy 2010;38:7338-45.

[10] Widén J, Wäckelgard E, Lund PD. Options for improving load matching capability of distributed photovoltaics: methodology and application to high-latitude data. Solar Energy 2009;83:1953-66.

[11] Zerhouni FZ, Zegrar M, Benmessaoud MT, Boudghene Stambouli A, Modoun A. Optimum load matching by an array reconfiguration in photovoltaic generators. Energy 2010;83:1953-66.

[12] Cellura M, Di Gangi A, Longo S, Orioli A. Photovoltaic electricity scenario analysis in urban contexts: an Italian case study. Renewable and Sustainable Energy Reviews 2012;16:2041-52.

[13] PVsyst, Software for photovoltaic systems, University of Geneva ISE-Group Energy, FOREL Battelle, bât. D7, route de Drize CH-1227 Carouge Switzerland.

[14] Dati Statistici sull'energia elettrica in Italia, Terna S.p.A., 〈www.terna.it/ default/Home/SISTEMA_ELETTRICO/statistiche/dati_statistici.aspx $\rangle$.

[15] Dati statistici ISTAT: Popolazione residente-Censimento 2001-Superficie delle abitazioni occupate da persone residenti, ISTAT, Italian National Institute of Statistics, dawinci.istat.it/MD/dawinciMD.jsp.

[16] Short W, Packey DJ, Holt T. A manual for the economic evaluation of energy efficiency and renewable energy technologies. Golden (Colorado, US): National Renewable Energy Laboratory; 1995.
[17] Borenstein S. The long-run efficiency of real-time electricity pricing. Energy Journal 2005;26:3

[18] Borenstein S. Electricity rate structures and economics of solar PV: could mandatory time-of-use rates undermine California's solar photovoltaic subsidies? Center for the Study of Energy Markets (CSEM), University of California Energy Institute, Berkeley campus; 2007.

[19] Voss K, Sartori I, Napolitano A, Geier S, Gonzalves H, Hall M, et al. Load matching and grid interaction of net zero energy buildings, EUROSUN 2010 , International Conference on Solar Heating, Cooling and Buildings, Graz, Austria, 29 September-1 October 2010.

[20] Verbruggen B, De Coninck R, Baetens R, Saelens D, Helsen L, Driesen J. Grid impact indicators for active building simulation. In: Proceedings of the IEEE PES conference on innovative smart grid technologies conference. Anaheim (California, US); 17-19 January 2011.

[21] Project EURECO demand-side management, end-use metring campaign in 400 households of the European community. Assessment of the potential electricity savings; 2002.

[22] eERG, end-use Efficiency Research Group, Politecnico di Milano, MICENE Misure dei consumi di energia elettrica in 110 abitazioni italiane, curve di carico dei principali elettrodomestici e degli apparecchi di illuminazione; 2004.

[23] IES, Institute for Environment and sustainability-JRC, Joint Research Centre-European Commission. Electricity consumption and efficiency trends in the enlarged European Union. Status report; 2006.

[24] IEA, International Energy Agency. Final report of Annex 42-energy conservation in buildings and community system programme; 2008.

[25] Gellings CW, Chamberlin JH. Demand-side management: concepts \&methods. The Fairmont Press, Inc.; 1993.

[26] Lorenz E, Scheidsteger T, Hurka J, Heinemann D, Kurz C. Regional PV power prediction for improved grid integration. Progress in Photovoltaics: Research and Applications 2011;19:757-71.

[27] Hachem C, Athienitis A, Fazio P. Parametric investigation of geometric form effects on solar potential of housing units. Solar Energy 2011;85:1864-77.

[28] Hachem C, Athienitis A, Fazio P. Design of roofs for increased solar potential of BIPV/T systems and their applications to housing units. ASHRAE Transactions 2012:R1 TRNS-00226-2011. 